\title{
Article \\ Vibration and Noise Exposure during Pre-Commercial Thinning Operations: What Are the Ergonomic Benefits of the Latest Generation Professional-Grade Battery-Powered Chainsaws?
}

\author{
Martin Huber ${ }^{1, *} \mathbb{\infty}$, Stephan Hoffmann ${ }^{2} \oplus$, Frauke Brieger ${ }^{1}$, Florian Hartsch ${ }^{3}$, Dirk Jaeger ${ }^{3}$ and Udo Hans Sauter ${ }^{1}$ \\ 1 Department of Forest Utilization, Forest Research Institute of Baden-Württemberg, \\ Wonnhaldestraße 4, 79100 Freiburg, Germany; frauke.brieger@forst.bwl.de (F.B.); \\ udo.sauter@forst.bwl.de (U.H.S.) \\ 2 Chair of Forest Operations, Faculty of Environment and Natural Resources, University of Freiburg, \\ Werthmannstraße 6, 79085 Freiburg, Germany; stephan.hoffmann@nibio.no \\ 3 Department of Forest Work Science and Engineering, Faculty of Forest Sciences and Forest Ecology, \\ University of Göttingen, Büsgenweg 4, 37077 Göttingen, Germany; florian.hartsch@uni-goettingen.de (F.H.); \\ dirk.jaeger@uni-goettingen.de (D.J.) \\ * Correspondence: martin.huber@forst.bwl.de
}

Citation: Huber, M.; Hoffmann, S.; Brieger, F.; Hartsch, F.; Jaeger, D.; Sauter, U.H. Vibration and Noise Exposure during Pre-Commercial Thinning Operations: What Are the Ergonomic Benefits of the Latest Generation Professional-Grade Battery-Powered Chainsaws? Forests 2021, 12, 1120. https://doi.org/ 10.3390/f12081120

Received: 13 July 2021

Accepted: 17 August 2021

Published: 21 August 2021

Publisher's Note: MDPI stays neutral with regard to jurisdictional claims in published maps and institutional affiliations.

Copyright: (C) 2021 by the authors. Licensee MDPI, Basel, Switzerland. This article is an open access article distributed under the terms and conditions of the Creative Commons Attribution (CC BY) license (https:// creativecommons.org/licenses/by/ $4.0 /)$.

\begin{abstract}
In order to compare the vibration and noise exposure of STIHL's battery-powered MSA $220 \mathrm{C}$ and the combustion driven MS $201 \mathrm{C}$, a professional operator was monitored during a precommercial thinning operation in a twenty-year-old hardwood stand. The vibration levels were measured with a tri-axial accelerometer on the front and rear handle of both the chainsaws, and assigned to five different work elements using a video documentation. Additionally, noise levels were recorded in one-minute intervals, with a dosemeter worn by the operator. The results show that battery-powered chainsaws, when compared to combustion-driven chainsaws, can reduce the daily vibration exposure by more than $45 \%$ and the noise dose by about $78.4 \%$, during pre-commercial thinning tasks. Replacing combustion-driven chainsaws with battery-powered ones is therefore generally recommended, to reduce occupational health risks for operators, in this respect. However, the daily vibration exposure of about $2.42 \mathrm{~m} / \mathrm{s}^{2}$, caused by the battery-powered chainsaw on the front handle, is still very close to the daily exposure action value set by the EU directives for health and safety requirements. The daily noise exposure of $89.18 \mathrm{~dB}(\mathrm{~A})$ even exceeds the upper exposure action value. Consequently, a further reduction in the vibration exposure during work is desirable. With respect to noise exposure, additional measures must be implemented for conformity with the current safety standards, making the use of hearing protectors mandatory for electric chainsaws, too.
\end{abstract}

Keywords: battery; chainsaw; vibration exposure; noise exposure; field study; pre-commercial thinning; health and safety

\section{Introduction}

Forest operations are, and always were, tedious and accident-prone, classifying forestry workers as an occupational group with a high risk of work-related injuries and illnesses [1]. Even today, with high occupational health and safety standards in the forestry sector, forest operations, in particular motor-manual tree felling, remain consistently dangerous [2].

The increasing share of mechanized harvesting systems improved the efficiency of operations, but also reduced the occupational health and safety risks, contributing to a reduction in fatal accidents and work strain in general. In consequence, fully-mechanized harvester-forwarder systems are state-of-the-art in commercial forest operations, outcompeting motor-manual operations in many European countries [3-5].

Yet, operational restrictions, such as terrain, legal regulations, stand size and structure, or silvicultural regimes, can often compromise the efficiency of fully mechanized harvesting 
systems. Such constraints, for instance, limit the application of fully mechanized operations, to only about $60 \%$ of the entire forest area in Germany [6]. Therefore, motor-manual operations will remain relevant and are applied in early pre-commercial thinning up to the final harvest of old growth stands [4]. However, the operators of motor-manual hand tools are directly exposed to the work environment, potentially causing discomfort through, e.g., weather and vegetation, but also fatigue, by moving in difficult terrain, with associated risks such as trip, slip and fall injuries [2].

Besides actual accidental risks, the long-term operation of motorized hand tools, in particular chainsaws, are a major issue of occupational health and safety concerns, due to ergonomic strain and physical fatigue [7]. Conventional chainsaws, with a combustion engine, directly expose the operator to considerable vibrations, noise, and emissions [8-11].

Chainsaw engines cause oscillated motion exposure to their operator, commonly known as vibration. The transmission to the operator, through the handles, is associated with various vascular, neurological, and musculoskeletal disorders, collectively called the "hand-arm vibration syndrome" [12]. Vibration-induced occupational risks are further exaggerated by coupling forces that are related to the saw type, wood properties, the individual biophysical traits, and the work technique of the operator [13,14]. The magnitude of these risks could already be reduced through the introduction of anti-vibration units for chainsaws in the 1970s [11]. Yet, the main source of chainsaw vibration is the back-and-forth movement of the piston [15], an indispensable component of conventional chainsaws with combustion engines, and therefore it is not possible to fully eliminate.

Next to vibrations, the operator's direct exposure to noise and emissions is determined by the constructural design of a combustion chainsaw, too, and reduction measures are limited. High-capacity chainsaws can cause engine noise levels up to $113 \mathrm{~dB}(\mathrm{~A})$ at full throttle, causing impairment of hearing during frequent exposure [16]. The combustion process of the internal engine produces exhaust fumes, which, although reduced in risk intensity through the use of alkylate fuels [17], induce direct strain to the operator [8], especially under unfavorable stand and weather conditions.

Electric power tools have advanced over the recent years, in terms of engine power, in particular with respect to batteries, and therefore seem to provide solutions to improve the ergonomics of chainsaw works. Neri et al. [18] investigated, under rather controlled conditions, vibration and noise exposure during log cross-cutting at the roadside, by two battery-powered and two cable-supplied electric saws. Carrying on, Poje et al. [10] compared the noise and vibration exposure of a battery-powered chainsaw and a conventional combustion engine-driven chainsaw, even during operational conditions in small-scale thinning. Both studies could already confirm reduced occupational health risks related to noise and vibration exposure. However, the subject of these studies was consumer-grade saws, intended for part-time users and not professional forest workers with high annual operation hours.

The focus on consumer-grade saws during earlier studies was owed to the situation that the battery saws that were available on the market were of low power and chain speed. However, the latest generation of battery-powered chainsaws, such as the STIHL MSA $220 \mathrm{C}$, with $36 \mathrm{~V}$ lithium-ion batteries and a chain speed of $23.3 \mathrm{~m} / \mathrm{s}$ [19], promise work capacities in the lower ranges of professional use, such as the tending of stands. A recent unpublished trial with the STIHL MSA $220 \mathrm{C}$, comparing it with its combustion counterpart MS $201 \mathrm{C}$, already confirmed its operational efficiency and competitiveness with conventional chainsaws, as long as it is used in its capacity limits [20].

Hence, the potential occupational health and safety benefits of the progressing electric counterparts of the current combustion engine-based tools must be assessed in further detail. Insights need to be gained into the overall context of sustainable forest operations [21], and improvement potentials need to be weighted. In order to contribute to this process, a focus on vibration and noise exposure mitigation, during the professional use of batterypowered chainsaws, is of special interest to the current study. Thus, the objectives of the study are as follows: (1) to directly compare the operator vibration and noise exposure of 
professional-grade battery and combustion engine chainsaws in pre-commercial thinning; (2) to quantify the ergonomic benefits for professional users, based on the daily exposure values for vibration and noise on shift level; (3) to draw conclusions about the potential of battery-driven chainsaws to replace combustion-driven ones in the near future, within professional forest operations.

\section{Materials and Methods}

\subsection{Setting}

A pilot field trial was conducted with a professional operator (27 years of job experience), comparing STIHL's high-performance battery-powered chainsaw MSA 220 C, and its combustion-driven counterpart MS $201 \mathrm{C}$ (Table 1), under operational conditions in a pre-commercial thinning.

Table 1. Specifications stated by the manufacturer of the STIHL MSA $220 \mathrm{C}$ and its lithium-ion battery AP $300 \mathrm{~S}$ as well as of the STIHL MS 201 C [19,22-25].

\begin{tabular}{|c|c|c|}
\hline & STIHL MSA $220 \mathrm{C}$ & STIHL MS 201 C \\
\hline Type & $\begin{array}{l}\text { Battery-powered chainsaw } \\
\text { with lithium-ion battery AP } \\
300 \mathrm{~S}\end{array}$ & $\begin{array}{l}\text { Petrol chainsaw with } \\
\text { single-cylinder two-stroke } \\
\text { engine }\end{array}$ \\
\hline Weight & $\begin{array}{c}3.6 \mathrm{~kg} \\
\text { (with guide bar and saw } \\
\text { chain, without battery and } \\
\text { saw chain adhesion oil) }\end{array}$ & $\begin{array}{c}4.54 \mathrm{~kg} \\
\text { (with guide bar and saw } \\
\text { chain, without fuel and saw } \\
\text { chain adhesion oil) }\end{array}$ \\
\hline Oil tank capacity & $0.21 \mathrm{~L}$ & $0.22 \mathrm{~L}$ \\
\hline Fuel tank capacity & - & $0.31 \mathrm{~L}$ \\
\hline Battery Weight & $1.8 \mathrm{~kg}$ & - \\
\hline $\begin{array}{c}\text { Voltage/Energy } \\
\text { content/Capacity according } \\
\text { to IEC } 61960\end{array}$ & $36 \mathrm{~V} / 281 \mathrm{Wh} / 7.2 \mathrm{Ah}$ & - \\
\hline Engine power & - & $1.8 \mathrm{~kW} / 2.4 \mathrm{hp}$ \\
\hline Guide bar length & $35 \mathrm{~cm}$ & $35 \mathrm{~cm}$ \\
\hline $\begin{array}{c}\text { Maximum chain speed } \\
\text { (6-tooth for } 3 / 8^{\prime \prime} \mathrm{P} \text { ) according } \\
\text { to ISO } 11681\end{array}$ & $23.3 \mathrm{~m} / \mathrm{s}$ & $26.0 \mathrm{~m} / \mathrm{s}$ \\
\hline Total gross mass & $5.64 \mathrm{~kg}$ & $4.98 \mathrm{~kg}$ \\
\hline
\end{tabular}

The experimental plot consisted of a twenty-year-old hardwood stand, located on a former windfall area within the forestry district Emmendingen/office Weisweil, in the Upper Rhine plains, close to the city of Breisach/Germany. The geographic coordinates of the plot are approximately $48^{\circ} 11^{\prime} 35^{\prime \prime} \mathrm{N}$ and $7^{\circ} 42^{\prime} 13^{\prime \prime} \mathrm{E}$. Due to intensive post-disturbance natural regeneration, stand-dominating tree species were European hornbeam (Carpinus betulus) and sycamore maple (Acer pseudoplatanus), complemented by planted wild cherry (Prunus avium) and common oak (Quercus robur).

The monitored operator was tasked to fell two or three trees next to each predefined and marked so-called potential future crop tree within this stand. In addition, dominant trees with negative characteristics were supposed to be cut, too. The diameter at base height of the felled trees ranged from $6 \mathrm{~cm}$ to $26 \mathrm{~cm}$ with the mean being approximately $13 \mathrm{~cm}$.

In order to create a practical and professional experimental set-up, the compared chainsaws were not factory-fresh, but of low operational use, well maintained and in excellent technical condition. Both chainsaws were equipped with new STIHL Oilomatic Picco Micro 3 (PM3) 3/8"-P saw chains. While the MS $201 \mathrm{C}$ was fueled by approved alkylate fuel, the MSA $220 \mathrm{C}$ was powered by STIHL's lithium-ion battery AP $300 \mathrm{~S}$, currently the brand's highest capacity battery.

The MSA $220 \mathrm{C}$ was chosen since it was, at the time of the study, the highest ranged battery-powered chainsaw by STIHL, and therefore the one most likely to be used by professional users. In accordance with this choice, the petrol chainsaw MS $201 \mathrm{C}$ was 
selected since it is of similar size and weight, has a comparable performance and is intended for similar areas of application.

During the 6th and 7th of June 2019, eight working cycles, four with each chainsaw, were conducted by the selected operator and monitored accordingly. The duration of one cycle was defined by the operating lifetime of one battery charge or one tank filling, respectively. Operating cycle time for both, the battery-powered and the combustion-driven saw, were very similar in duration as the preceding unpublished study already showed [20]. For the MSA $220 \mathrm{C}$, a new and fully charged battery was used for each cycle. Accordingly, the MS $201 \mathrm{C}$ was refueled completely by the operator before each cycle. While the noise exposure was measured during all eight cycles, the vibration exposure was only recorded on one handle during each cycle. On both days, the first cycle was used to measure the vibrations on the front handle of the MSA $220 \mathrm{C}$ and the second for the vibrations on the rear handle. The third and fourth cycles were used to record the vibrations on the front and rear handle of the MS $201 \mathrm{C}$, respectively. To avoid an influence of the condition of the saw chain on the vibration measurements [26,27], a factory-fresh saw chain was used for each cycle. It was mounted and tensioned each time by the operator himself.

\subsection{Vibration Exposure}

Vibration exposure measurements were conducted based on [28,29] ("Mechanical vibration -Measurement and evaluation of human exposure to hand-transmitted vibration-Part 1: General requirements" and "Mechanical vibration-Measurement and evaluation of human exposure to hand-transmitted vibration-Part 2: Practical guidance for measurement at the workplace"). Yet, several adjustments had to be made, owed to the available equipment and constraints caused by the field study character, not allowing controlled conditions such as in a laboratory.

As requested by these standards, equipment that is in compliance with ISO 8041:2005 "Human response to vibration-Measuring instrumentation" was used for recording the hand-arm vibrations, namely, the human vibration analyzer type 4447 from Brüel \& Kjaer (Brüel \& Kjaer Sound \& Vibration Measurement A/S, Naerum/Denmark) in combination with Brüel \& Kjaer's triaxial, piezoelectric accelerometer type 4520-002 [30,31]. The accelerometer measures the acceleration in three pairwise perpendicular directions simultaneously. It thereby records, among other data, the peak values and the RMS values (root mean square values) in a time interval of one second [32]. These values are frequencyweighted in accordance with ISO 8041:2005 [32]. The main quantities regarded in this study are the RMS values in each direction and the RMS VTV (root mean square vibration total value), which is defined as the square root of the sum of squares of the RMS values in the three measuring directions, i.e., the following:

$$
a_{\mathrm{hv}}=\sqrt{a_{\mathrm{hwx}}^{2}+a_{\mathrm{hwy}}^{2}+a_{\mathrm{hwz}}^{2}}
$$

where $a_{\mathrm{hv}}$ is the RMS VTV in $\mathrm{m} / \mathrm{s}^{2}$ and $a_{\mathrm{hwx}}, a_{\mathrm{hwy}}$ and $a_{\mathrm{hwz}}$ are the RMS values in the $\mathrm{x}-$, $\mathrm{y}$ - and $\mathrm{z}$-direction in $\mathrm{m} / \mathrm{s}^{2}$, respectively [28]. This means each of the measuring directions is weighted equally as prescribed by [28].

The vibration level for $N$ measurements is given by the following:

$$
a_{\mathrm{hv}}=\sqrt{\frac{1}{T} \sum_{j=1}^{N} a_{\mathrm{hv} j}^{2} t_{j}}
$$

where $N$ is the number of measurements, $a_{\mathrm{hv}}$ the resulting vibration level of the $N$ measurements in $\mathrm{m} / \mathrm{s}^{2}, a_{\mathrm{hv} j}$ the RMS VTV of the $j^{\text {th }}$ measurement in $\mathrm{m} / \mathrm{s}^{2}, t_{j}$ the duration of the $j^{\text {th }}$ measurement in seconds and $\mathrm{T}$ the total duration of the $N$ measurements in seconds [29].

Since the measuring interval of each measurement was one second, the right-hand side of Equation (1) is reduced to the root mean square of the RMS VTVs of the single 
measurements. The resulting vibration level is therefore referred to as RMS VTV of the $N$ measurements.

When assessing the health risk of hand-arm vibrations regarding a certain work, the vibration total values are not sufficient. Another key factor is the exposure time. The higher the vibration total values, the shorter the exposure time has to be to limit the health risks. To quantify the risks and to be able to compare vibration exposures, the daily vibration exposure value $A(8)$ is used. It is defined as follows:

$$
A(8)=\sqrt{\frac{1}{T_{0}} \sum_{i=1}^{N} a_{\mathrm{hv} i}^{2} T_{i}}
$$

where $N$ is the number of different tasks performed, $a_{\mathrm{hv} i}$ is the RMS VTV for the $i^{\text {th }}$ task in $\mathrm{m} / \mathrm{s}^{2}, T_{i}$ the duration of the $i^{\text {th }}$ task in minutes and $T_{0}$ is the reference value of $480 \mathrm{~min}$ (one standard working day of eight hours) [29]. Accordingly, for each task $i$, the partial vibration exposure is defined as follows:

$$
A_{i}(8)=a_{\mathrm{hvi}} \sqrt{\frac{T_{i}}{T_{0}}} \quad[29] .
$$

Therefore, the following applies:

$$
A(8)=\sqrt{\sum_{i=1}^{N} A_{i}^{2}(8)} .
$$

As soon as the daily vibration exposure value exceeds the exposure action value of $2.5 \mathrm{~m} / \mathrm{s}^{2}$ the employer is obliged to take measures to reduce the vibration exposure to a minimum. The daily vibration exposure must not exceed the exposure limit value of $5 \mathrm{~m} / \mathrm{s}^{2}[33]$.

For the vibration measurements the accelerometer was mounted on Brüel \& Kjaer's cube adapter UA-3017 [31], which in turn was clamped to the handle of the chainsaw by cable ties as is proposed by [29]. On the front handle the sensor had to be placed at the outermost part of the horizontal crossbar to avoid interference with the workflow of the operator (Figure 1). The position is very close to the one prescribed by [34] ("Forestry and gardening machinery-Vibration test code for portable hand-held machines with internal combustion engine-Vibration at the handles") and [35] ("Hand-held motor-operated electric tools-Safety-Part 2-13: Particular requirements for chain saws"), but is a few centimeters off to the right. Because of ergonomic and safety reasons, the accelerometer could not be positioned in compliance with the two norms at the rear handle. Instead of the position right above the user's hand, a position proposed by [29], right underneath the user's hand, was chosen to measure the vibrations as close to the user's hand as possible (Figure 1). Since just one accelerometer was available, only the vibrations on one of the handles could be measured at a time and the sensor had to be mounted anew before each cycle.

A tool-based basicentric coordinate system, which was defined by the three measuring directions of the accelerometer, was used to measure vibrations [34] (Figure 1). Since the attachment of the sensor to the handles affected the orientation of the three measuring directions, care had to be taken that the sensor was orientated correctly. On the rear handle, the axes were in accordance with [34]. At the front handle, the measuring axes were offset by several degrees due to the shape of the handle and the position of the sensor at the handle. Additionally, it was necessary that the cable of the sensor would not interfere with the workflow of the operator, nor get disconnected from the vibration analyzer attached to his belt. For this reason, axes had to be interchanged compared to the DIN standard. Nonetheless, one measuring direction was always in line with the measuring directions 
according to [34]. For comparability with other studies, the results were adjusted to fit the naming of the axes used in the DIN standard, as is depicted in Figure 1.
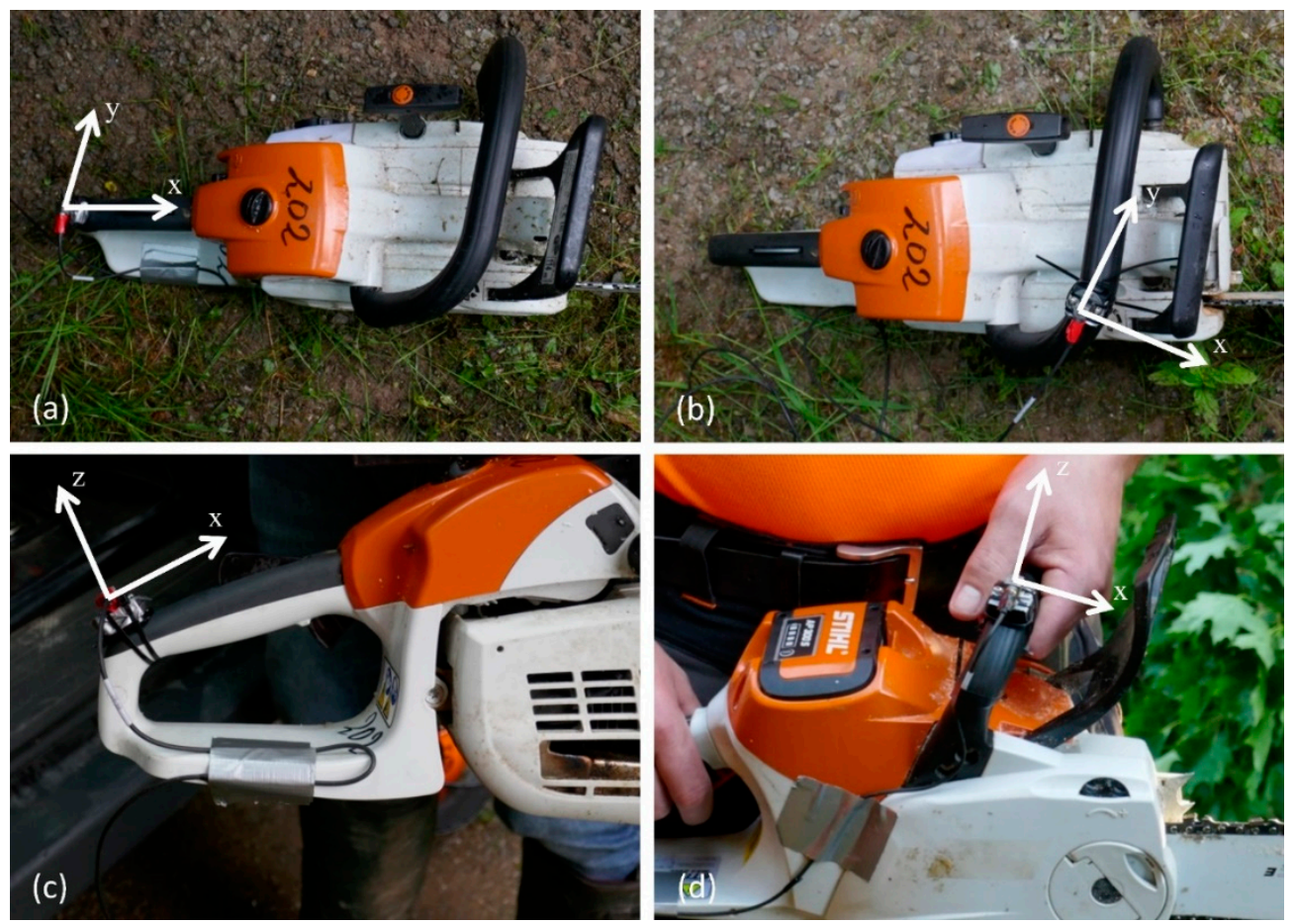

Figure 1. Visualization of the basicentric coordinate system used for the vibration measurements when the sensor is mounted on the rear and front handle. (a) Rear handle top view; (b) front handle top view; (c) rear handle side view; (d) front handle side view.

To evaluate the vibration levels during different operating stages, a similar approach as in [36] was used, as follows: The whole sequence of events of the cycles was filmed in order to match the operator's actions with the corresponding vibration values, using a GoPro Hero 2, attached to the operator via a chest strap. The actions were grouped in five work elements and the RMS VTVs, the exposure time and the partial vibration exposure were determined for each of them. The definition of the different work elements was as follows:

1. Sawing: The period from pulling the throttle trigger of the chainsaw under load up to releasing it.

2. Actions related to sawing: All actions that were directly related to the sawing process, such as pressing the throttle trigger in mid-air before sawing or repositioning the chainsaw between two consecutive cuts.

3. Walking and orientation: All periods when the operator oriented himself in the stand, walked from one tree to another or walked to perform the next cut. During walking the chainsaw was held by both hands.

4. Saw held on one handle: All periods when, due to the experimental set-up, the chainsaw was held on only one handle. These periods mainly included actions, such as, for example, pushing down sawn-off trees or laying them aside.

5. Interruptions of the productive work time and faulty measurements: All periods during which the productive work time was interrupted, for example due to the experiment or due to technical issues, e.g., when the saw chain had to be reattached after jumping off. Additionally, all faulty measurements, such as, for example, when a small branch hit the sensor.

Only correct measurements caused by the chainsaw and its handling and only actions belonging to the productive work time were considered for the computation of the vibration 
exposure. Therefore, the actions belonging to work element five were excluded from the evaluation. For work element four, only the exposure time was considered, since the vibration values only occurred because of the experimental set-up [37]. The cable of the measurement equipment, which connected the operator with the chainsaw, prevented the prescribed workflow for example when starting the chainsaw or pushing down trees. Because of ergonomic and safety reasons, the operator should normally put down the saw during these activities [38], hence, he is not exposed to any vibrations of the chainsaw at all. Therefore, the RMS VTVs during these activities were set to zero for the calculation of the RMS VTV of the full working day and the calculation of the daily vibration exposure. The cable was also the reason why it was hardly possible to carry the chainsaw with one hand during work element three.

To calculate the daily vibration exposure, the exposure time during a full working day needed to be assessed. Therefore, aside from the productive work time for the vibration exposure, which was determined from the video, delay and service times had to be considered. A fixed percentage of about $40 \%$ of the productive work time was considered for these times [20]. Leading to a relation of about $71.4 \%$ productive work time and about $28.6 \%$ delay and service times when regarding a full working day. It was assumed that the operator was not exposed to any hand-arm vibrations during the delay and service times, and therefore the RMS VTVs of these times entered the calculations with a value of zero.

\subsection{Noise Exposure}

In addition to the vibration exposure caused by the two chainsaws, the basic noise exposure of the operator was examined. For this, the equivalent continuous A-weighted sound pressure level $L_{\mathrm{Aeq}}$ of one-minute intervals as well as the peak $C$-weighted sound pressure level $L_{\mathrm{CPeak}}$ of each interval were recorded. The equivalent continuous sound pressure level $L_{\text {Aeq }}$ is defined by the constant noise level, which over the duration of the measuring interval would contain the same amount of energy as the actual noise during this interval [39]. It is A-weighted, i.e., the sound pressure levels are weighted according to their frequency, taking the risks for human hearing and the annoyance perceived by humans into account [40]. The peak sound pressure level $L_{\mathrm{CPeak}}$ is defined as the maximum sound pressure level occurring during the measuring period. In contrast to the $L_{\mathrm{Aeq}}$ it is C-weighted, i.e., low frequencies are weighted much higher than in the A-weighting [40].

As with the hand-arm vibrations, the exposure time is, aside from the equivalent continuous sound pressure level, the decisive quantity to assess the health risks of noise exposure. Similar to the daily vibration exposure value $A(8)$, the daily noise exposure level $L_{\mathrm{Ex}, 8 \mathrm{~h}}$ is used to quantify the noise exposure during one working day. The definition accounts for the logarithmic scale of the decibel as follows:

$$
L_{\mathrm{Ex}, 8 \mathrm{~h}}=10 \cdot \log \left(\sum_{i=1}^{N} \frac{T_{i}}{T_{0}} 10^{0.1 \cdot L_{\mathrm{Aeq}, i}}\right)
$$

where $N$ is the number of different tasks performed, $T_{i}$ the duration of the $i^{\text {th }}$ task in minutes, $T_{0}$ the reference value of $480 \mathrm{~min}$ (one standard working day of eight hours) and $L_{\mathrm{Aeq}, i}$ the equivalent continuous sound pressure level of the $i^{\text {th }}$ task in $\mathrm{dB}(\mathrm{A})$ [41].

If the $L_{\mathrm{Ex}, 8 \mathrm{~h}}$ exceeds the upper exposure action value of $85 \mathrm{~dB}(\mathrm{~A})$, the employer is obliged to take certain actions to reduce the noise exposure of the operator. Taking the attenuation of hearing protectors into account, the operator shall never be exposed to a daily noise exposure level above the exposure limit value of $87 \mathrm{~dB}(\mathrm{~A})$ [42]. In Germany the rules are even stricter. Considering hearing protectors, the "Lärm- und VibrationsArbeitsschutzverordnung-LärmVibrationsArbSchV" defines a maximum permissible daily noise exposure level of $85 \mathrm{~dB}(\mathrm{~A})$ at the ear [43]. The further results, however, relate to the $87 \mathrm{~dB}(\mathrm{~A})$ exposure limit value defined by the European Union.

As measuring device for the noise exposure, Casella's (IDEAL Industries Inc., Sycamore, IL, USA) noise dosemeter CEL-35X with a fast time weighting was used. It was combined 
with Casella's microphone CEL-252, which is classified as type 2, and with Casella's windshield CEL-6356 [39]. Altogether, the equipment allows measurements in compliance with DIN EN ISO 9612:2009-09 "Acoustics-Determination of occupational noise exposure-Engineering method" [44].

The dosemeter was fixed with a Velcro on a special shoulder strap, allowing a positioning of the measuring device at the top of the operator's shoulder as defined in [41].

For the computation of the daily noise exposure level, an equivalent continuous sound pressure level for the productive work time of each cycle was computed. Since each measuring interval was of the same length, the equation for the equivalent continuous sound pressure level [40] reduces in this case to the following:

$$
L_{\text {Aeq, Cycle }}=10 \cdot \log \left(\sum_{i=1}^{N} \frac{1}{N} 10^{0.1 \cdot L_{\text {Aeq }, i}}\right)
$$

where $N$ is the number of measuring intervals for the productive work time of the cycle and $L_{\mathrm{Aeq}, i}$ the equivalent continuous sound pressure level of the $i^{\text {th }}$ measuring interval in $\mathrm{dB}(\mathrm{A})$.

The productive work time for the noise exposure was mainly determined from the video footage and partly from manually measured times. Since the length of the measuring periods was one minute, several intervals included not only productive work time, but also delay and service times or interruptions. Therefore, these intervals had to be excluded from the evaluation to get the correct equivalent continuous sound pressure level of the productive work time.

As for the vibration measurements, the delay and service times were considered with a fixed percentage of $40 \%$ of the productive work time, too [20]. It was assumed that during this time the operator was exposed to the environmental noise of the experimental plot, which was estimated by using the average of the equivalent continuous sound pressure levels recorded during breaks.

Using the equivalent continuous sound pressure level for the productive work time and for the delay and service times, Equation (2) was applied to compute the daily noise exposure level.

Additionally, the dose was considered using a criterion level of $87 \mathrm{~dB}(\mathrm{~A})$ and an exchange rate of $3 \mathrm{~dB}$, i.e., since discrete intervals were regarded, the dose $D$ can be calculated by the following:

$$
D=\sum_{i=1}^{N} \frac{100 \%}{8 \mathrm{~h}} t_{i} 2^{\left(\frac{L_{\mathrm{Aeq}, i}-87 d B(A)}{3 d B}\right)}
$$

where $D$ is the dose, $N$ the number of measured equivalent continuous sound pressure levels, $t_{i}$ the duration of the $i^{\text {th }}$ measuring period in hours and $L_{\mathrm{Aeq}, i}$ the equivalent continuous sound pressure level of the $i^{\text {th }}$ measuring period in $\mathrm{dB}(\mathrm{A})[45,46]$. Accordingly, a noise exposure with an equivalent continuous sound pressure level in the amount of the exposure limit value of $87 \mathrm{~dB}(\mathrm{~A})$, for a full working day of $8 \mathrm{~h}$, corresponds to a dose of $100 \%$. For the calculations of the dose no threshold was applied [46].

\subsection{Analysis Tools}

The basic data preparation was conducted in context of the master thesis of Robin Feldmann [47] using the software "Vibration Explorer Software BZ-5623" from Brüel \& Kjaer, "Insight" from Casella and "Microsoft Excel". The data analysis and visualization were performed using "Microsoft Excel" and the programming language and software environment $R$ together with the development environment RStudio $[48,49]$. For the part written in R, aside from the standard R packages, the packages "openxlsx", "ggplot2" and "ggpubr" were used [50-52]. 


\section{Results}

To be able to classify and interpret the vibration and noise exposure correctly, Table 2 gives an overview of the performance data captured during the trial. The data are separated by the type of chainsaw and the position of the accelerometer, i.e., the data of the cycles one and five, two and six, three and seven, as well as four and eight, are aggregated, leading to four different configurations.

Table 2. Performance data for the eight cycles aggregated by the type of chainsaw and the position of the accelerometer [47].

\begin{tabular}{|c|c|c|c|c|}
\hline \multirow{2}{*}{$\frac{\text { Accelerometer Position }}{\text { Chainsaw }}$} & \multicolumn{2}{|c|}{ Front Handle } & \multicolumn{2}{|c|}{ Rear Handle } \\
\hline & MSA $220 \mathrm{C}$ & MS $201 \mathrm{C}$ & MSA $220 \mathrm{C}$ & MS $201 \mathrm{C}$ \\
\hline Area [ha] & 0.37 & 0.35 & 0.35 & 0.24 \\
\hline Real productive work time $[\mathrm{min}]$ & 75.58 & 61.90 & 73.55 & 77.55 \\
\hline Productive work time for vibration exposure [min] & 75.58 & 56.48 & 73.55 & 70.27 \\
\hline Productive work time for noise exposure [min] & 61 & 54 & 58 & 70 \\
\hline Workplace time [min] (28.6\% delay and service times) & 105.8 & 86.7 & 103.0 & 108.6 \\
\hline Number of trees felled & 80 & 93 & 90 & 97 \\
\hline Mean diameter at base height $[\mathrm{cm}]$ & 13.8 & 12.0 & 14.1 & 13.9 \\
\hline Number of cuts & 237 & 239 & 236 & 264 \\
\hline
\end{tabular}

At the end of the seventh and the beginning of the eighth cycle, technical issues arose. Therefore, video material for the last $5.42 \mathrm{~min}$ of the seventh cycle and the first $7.28 \mathrm{~min}$ of the eighth cycle is missing. Consequently, these sequences had to be excluded from the in-depth analysis of the vibration values, reducing the productive work time for the vibration measurements on the front handle and rear handle of the MS $201 \mathrm{C}$.

For the noise exposure, the missing, but necessary, data could be replaced by manually measured data. However, due to the excluded measuring intervals, the real productive work time is reduced by nearly $15 \%$.

Since the further results for the vibration and noise exposure are based on relative times and values, and not on totals, these missing data do not bias the results' interpretation.

\subsection{Vibration Exposure}

The total productive work time that was assigned to each of the four relevant work elements, as well as the resulting time share, is stated in Table 3. The time share differs naturally for the four configurations, but its magnitude is roughly similar for each. About half of the time, the operator is walking or orientating himself, while almost one third of the time is spent sawing. For roughly $15 \%$ of the time, the saw is held with one hand, because of the experimental set-up. The rest of the time is assigned to activities that are, in a broader sense, connected to sawing.

Regarding the root mean square of the vibration total values for the different work elements and configurations in Table 3, huge differences between the two chainsaws are noticed. Only the vibration total value for the front handle when sawing is nearly identical for both, differing by just $0.6 \%$, with a slight advantage for the MS $201 \mathrm{C}$. On the rear handle, the RMS VTV of the MS $201 \mathrm{C}$ when sawing is $62.7 \%$ higher than the one of the battery-powered MSA $220 \mathrm{C}$. For the third work element "Walking and orientation", the difference is the largest. The combustion-driven MS $201 \mathrm{C}$ exceeds the values of the MSA $220 \mathrm{C}$ by $622.7 \%$ and $632.6 \%$ at the front and rear handle, respectively. Considering the RMS VTV of the MS $201 \mathrm{C}$ for work element two "Actions related to sawing", the values of the MS $201 \mathrm{C}$ are considerably higher, too, exceeding the ones of the MSA $220 \mathrm{C}$ by $163.4 \%$ and $155.2 \%$ for the front and rear handle, respectively. As already mentioned, the measured RMS VTVs of work element four were not considered for the evaluation, since these values only occurred due to the experimental set-up. Instead, a vibration level of zero was assumed. 
Table 3. Exposure time and RMS VTVs as well as the resulting partial vibration exposure for the different work elements divided by type of chainsaw and sensor position.

\begin{tabular}{|c|c|c|c|c|c|c|c|c|c|c|c|}
\hline \multicolumn{2}{|c|}{ Work Element } & \multicolumn{2}{|c|}{ Total } & \multicolumn{2}{|c|}{ Sawing } & \multicolumn{2}{|c|}{$\begin{array}{l}\text { Actions Related to } \\
\text { Sawing }\end{array}$} & \multicolumn{2}{|c|}{$\begin{array}{l}\text { Walking and } \\
\text { Orientation }\end{array}$} & \multicolumn{2}{|c|}{$\begin{array}{l}\text { Saw Held On One } \\
\text { Handle }\end{array}$} \\
\hline & $\begin{array}{l}\text { Handle } \\
\text { Chainsaw }\end{array}$ & $\begin{array}{c}\text { Front } \\
\text { Handle }\end{array}$ & $\begin{array}{c}\text { Rear } \\
\text { Handle }\end{array}$ & $\begin{array}{c}\text { Front } \\
\text { Handle }\end{array}$ & $\begin{array}{c}\text { Rear } \\
\text { Handle }\end{array}$ & $\begin{array}{c}\text { Front } \\
\text { Handle }\end{array}$ & $\begin{array}{c}\text { Rear } \\
\text { Handle }\end{array}$ & $\begin{array}{c}\text { Front } \\
\text { Handle }\end{array}$ & $\begin{array}{c}\text { Rear } \\
\text { Handle }\end{array}$ & $\begin{array}{c}\text { Front } \\
\text { Handle }\end{array}$ & $\begin{array}{c}\text { Rear } \\
\text { Handle }\end{array}$ \\
\hline \multirow{2}{*}{ Productive work time [min] } & MSA $220 \mathrm{C}$ & 75.58 & 73.55 & 25.80 & 27.73 & 4.45 & 5.58 & 34.10 & 34.75 & 11.23 & 10.48 \\
\hline & MS 201 C & 56.48 & 70.27 & 16.72 & 22.95 & 3.68 & 2.63 & 26.65 & 35.98 & 9.43 & 8.70 \\
\hline \multirow{2}{*}{$\begin{array}{c}\text { Time share (productive work } \\
\text { time) }[\%]\end{array}$} & MSA 220 C & 100 & 100 & 34.1 & 30.9 & 5.9 & 7.6 & 45.1 & 47.3 & 14.9 & 14.3 \\
\hline & MS 201 C & 100 & 100 & 29.6 & 32.7 & 6.5 & 3.8 & 47.2 & 51.2 & 16.7 & 12.4 \\
\hline \multirow{2}{*}{$\begin{array}{c}\text { RMS VTV productive work } \\
\text { time }\left[\mathrm{m} / \mathrm{s}^{2}\right]\end{array}$} & MSA $220 \mathrm{C}$ & 2.86 & 2.36 & 4.64 & 3.94 & 2.79 & 2.23 & 0.88 & 0.92 & & \\
\hline & MS $201 \mathrm{C}$ & 5.37 & 6.16 & 4.61 & 6.41 & 7.35 & 5.69 & 6.36 & 6.74 & & \\
\hline $\begin{array}{l}\text { Difference of RMS VTVs during } \\
\text { productive work time [\%] }\end{array}$ & $\begin{array}{c}\text { MS } 201 \text { C compared to } \\
\text { MSA } 220 \text { C }\end{array}$ & +87.8 & +161.0 & -0.6 & +62.7 & +163.4 & +155.2 & +622.7 & +632.6 & & \\
\hline Partial/Daily Vibration & MSA $220 \mathrm{C}$ & 2.42 & 1.99 & 2.29 & 1.85 & 0.57 & 0.52 & 0.50 & 0.53 & & \\
\hline Exposure $\left[\mathrm{m} / \mathrm{s}^{2}\right]$ & MS $201 \mathrm{C}$ & 4.54 & 5.20 & 2.12 & 3.10 & 1.59 & 0.93 & 3.69 & 4.08 & & \\
\hline $\begin{array}{c}\text { Difference in partial vibration } \\
\text { exposure }[\%]\end{array}$ & $\begin{array}{c}\text { MS } 201 \mathrm{C} \text { compared to } \\
\text { MSA } 220 \mathrm{C}\end{array}$ & +87.6 & +161.3 & -7.4 & +67.6 & +178.9 & +78.8 & +638.0 & +669.8 & & \\
\hline
\end{tabular}


Comparing the vibration total values of the work elements with the exposure action and limit values for the daily vibration exposure, the MS $201 \mathrm{C}$ exceeds the limit value at the rear handle for each work element. At the front handle, only the RMS VTV for sawing is beneath the limit value, but the difference is only about $8 \%$. The situation changes when working with the MSA $220 \mathrm{C}$. Its RMS VTVs are below the limit value for each work element and both handles. For work element three, the values are not even close to the action value. Yet, during sawing, the vibration total values by far exceed the action value and approach the limit value, falling short of it by $7.8 \%$ at the front, and by $26.9 \%$ at the rear handle. For the second work element, the values are very close to the action value, exceeding it by about $11 \%$ at the front handle and falling below it by about $11 \%$ at the rear handle.

A more detailed view for the three relevant work elements is displayed in Figure 2, in the form of a box plot combined with a dot plot of the RMS VTVs for the front and rear handle of both chainsaws, respectively. There, the high amount of RMS VTVs above $10 \mathrm{~m} / \mathrm{s}^{2}$, measured at the front handle of the MS $201 \mathrm{C}$ for work element two and at its rear handle for work element one, especially stands out.
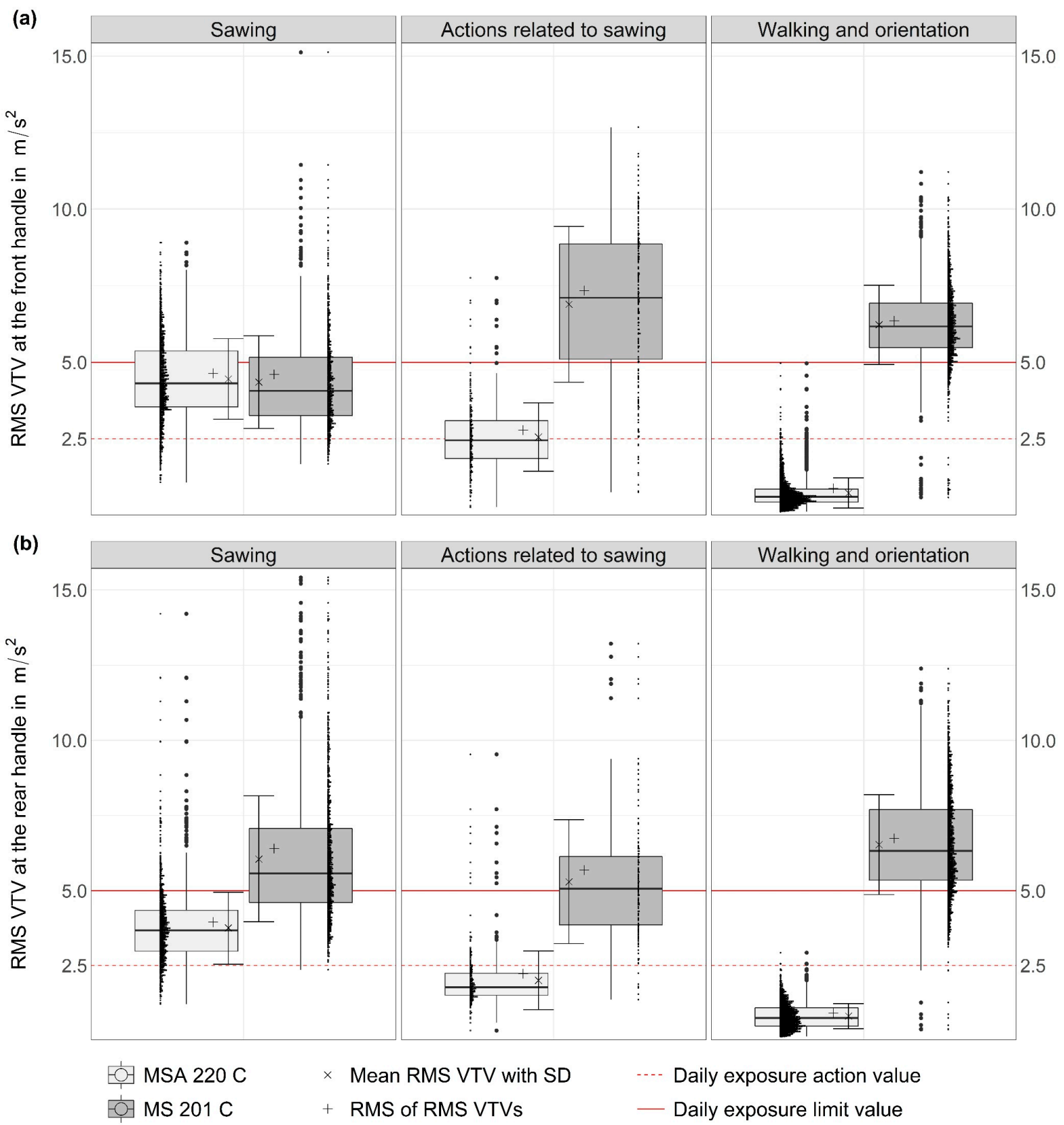

Figure 2. RMS VTVs of both chainsaws separated by the type of activity (a) for the front handle (b) for the rear handle. 
Combining the exposure times and vibration values for the relevant work elements and configurations, and considering the assumed $28.6 \%$ of delay and service times, results in the partial and daily vibration exposures that are displayed in Figure 3. For work element four, only the exposure time was considered, since its partial vibration exposure is assumed to be zero under normal conditions.

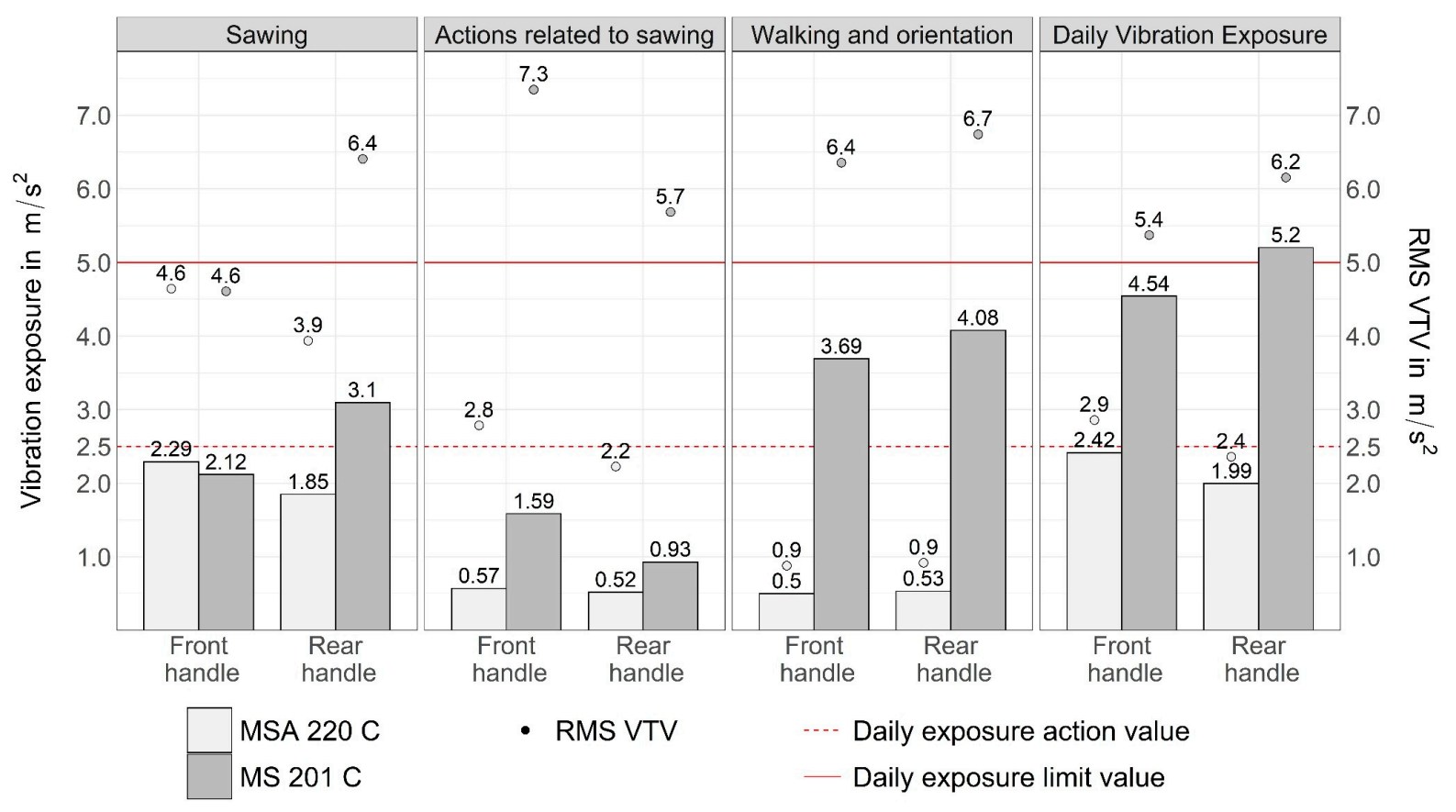

Figure 3. Partial daily vibration exposures of the different work elements and the resulting daily vibration exposure. The dots mark the respective RMS VTV.

Since the time share for the three work elements does not vary much for the different configurations, the difference in the partial vibration exposure of the MS $201 \mathrm{C}$, compared to the MSA $220 \mathrm{C}$, is very similar to the difference of the vibration total values for the three work elements (Table 3). Regarding the MSA 220 C, the work elements two and three show a very similar partial vibration exposure, which is at least $75 \%$ and $71 \%$ below the partial vibration exposure of work element one at the front and rear handle, respectively. Consequently, the daily vibration exposure differs only slightly from the partial vibration exposure of sawing. On both handles, the $A(8)$ value is below the exposure action value, but on the front handle it is only by about $3.3 \%$.

For the MS 201 C, the partial vibration exposure of the third work element "Walking and orientation" is predominant, exceeding the next highest work element by $74.1 \%$ on the front handle and by $31.6 \%$ on the rear handle. Still, the partial vibration exposure of the other two work elements is not negligible. For work element one "Sawing", it even surpasses the daily exposure action value by nearly $20 \%$, and on the rear handle it is only below it by about $18 \%$.

The resulting daily vibration exposure on the rear handle exceeds the daily exposure limit value by nearly $4 \%$. On the front handle, it exceeds the daily exposure action value by about $81.6 \%$ and falls short of the daily exposure limit value by roughly $10 \%$.

\subsection{Noise Exposure}

For the comparison of the noise exposure caused by both chainsaws, the measured noise levels of the four cycles performed with each chainsaw were aggregated, respectively. The productive work time, which could be used for the calculation of the noise exposure, the equivalent continuous sound pressure level during this time, as well as the mean and maximum peak values of the one-minute intervals, are presented in Table 4. 
Table 4. Summary of noise measurements.

\begin{tabular}{cccc}
\hline & MSA 220 C & MS 201 C & $\begin{array}{c}\text { Difference } \\
\text { (MS 201 C Compared to MSA 220 C) }\end{array}$ \\
\hline Productive work time $[\mathrm{min}]$ & 119 & 124 & $+5 \mathrm{~min}$ \\
$L_{\text {Aeq }}$ productive work time $[\mathrm{dB}(\mathrm{A})]$ & 90.64 & 97.28 & $+6.64 \mathrm{~dB}(\mathrm{~A})$ \\
Mean $L_{\mathrm{CPeak}}[\mathrm{dB}(\mathrm{C})]$ & 113.10 & 118.83 & $+5.73 \mathrm{~dB}(\mathrm{C})$ \\
Maximum $L_{\mathrm{CPeak}}[\mathrm{dB}(\mathrm{C})]$ & 122.1 & 121.5 & $-0.6 \mathrm{~dB}(\mathrm{C})$ \\
$L_{\mathrm{Ex}, 8 \mathrm{~h}}[\mathrm{~dB}(\mathrm{~A})](28.6 \%$ delay and service & 89.18 & 95.81 & $+6.63 \mathrm{~dB}(\mathrm{~A})$ \\
time with an $L_{\text {Aeq }}$ of $\left.65.43 \mathrm{~dB}(\mathrm{~A})\right)$ & 165.5 & 767.4 & $+363.7 \%($ relative difference) \\
Dose full working day $[\%]$ & & & \\
\hline
\end{tabular}

The productive work time, and therefore the number of measurements, is very similar, differing by about $4.2 \%$ only. The $L_{\text {Aeq }}$ of the combustion chainsaw is about $6.64 \mathrm{~dB}(\mathrm{~A})$ higher than the one of the battery chainsaw, leading, for the same exposure time, to about a 4.6-times higher dose. Regarding the mean $L_{C P e a k}$, a difference of $5.73 \mathrm{~dB}(C)$, in favor of the battery-powered chainsaw, is detected. Nevertheless, the maximum peak value of the MSA $220 \mathrm{C}$ surpasses the one of the MS $201 \mathrm{C}$ by about $0.6 \mathrm{~dB}(\mathrm{C})$.

A more thorough representation is given in Figure 4. It displays a box plot combined with a dot plot of the peak sound pressure levels and of the equivalent continuous sound pressure levels of the measuring intervals for both chainsaws. Especially noticeable is the relatively large distance in mean $L_{\mathrm{CPeak}}$ and median $L_{\mathrm{CPeak}}$ for the MSA $220 \mathrm{C}$, which is caused by several outliers, whose sound pressure level is considerably higher than the ones of the other values. Looking at the $L_{\mathrm{Aeq}}$, there are nearly no outliers at the top, but several at the bottom. Nevertheless, nearly all the measured values exceed the upper exposure action value, and most often even exceed the exposure limit value.
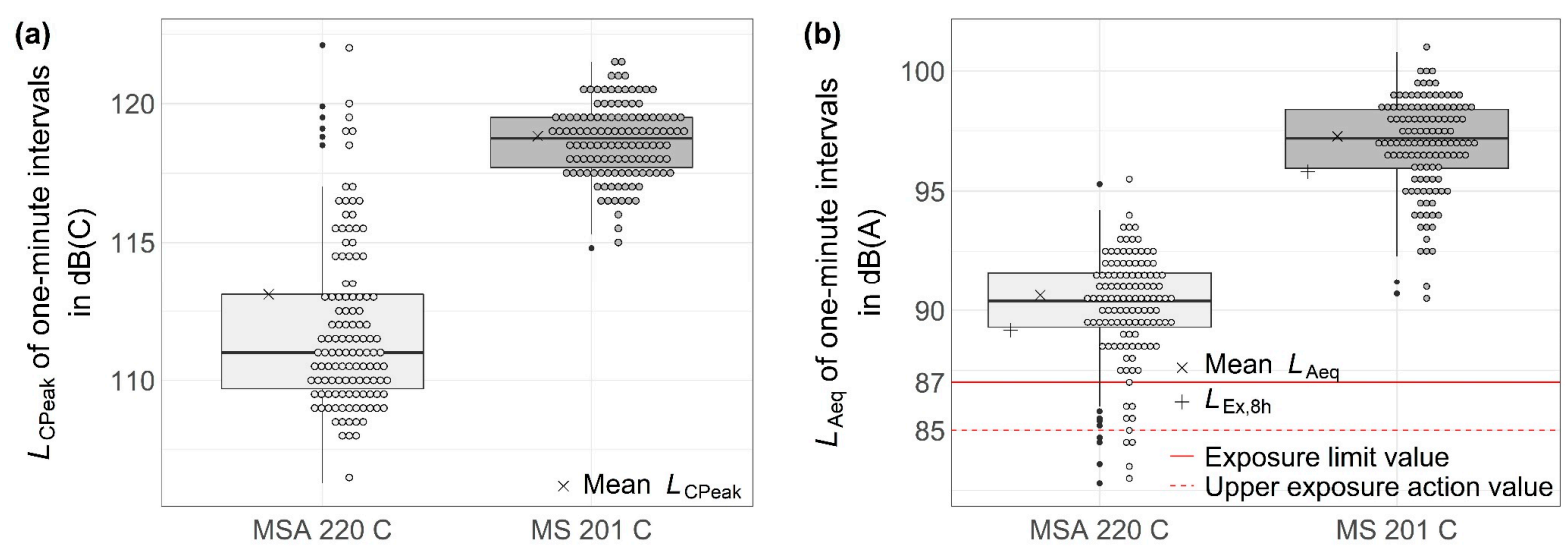

Figure 4. (a) $L_{\mathrm{CPeak}}$ values (b) $L_{\mathrm{Aeq}}$ values of the one-minute measuring intervals.

During the breaks, an equivalent continuous sound pressure level of $65.43 \mathrm{~dB}(\mathrm{~A})$ was measured. Therefore, presuming $71.4 \%$ of productive work time during an eight-hour day, i.e., about $5: 43 \mathrm{~h}$, and assuming an equivalent continuous sound pressure level of $65.43 \mathrm{~dB}(\mathrm{~A})$ during the remaining time, the daily noise exposure level for the MS $201 \mathrm{C}$ reaches $95.81 \mathrm{~dB}(\mathrm{~A})$, whereas the one for the MSA $220 \mathrm{C}$ reaches $89.18 \mathrm{~dB}(\mathrm{~A})$. Even though the dose for the battery-powered chainsaw for the full working day is less than one quarter of the dose for the combustion-driven chainsaw, the $L_{\mathrm{Ex}, 8 \mathrm{~h}}$ for both the chainsaws exceeds the legal exposure limit value of $87 \mathrm{~dB}(\mathrm{~A})$ if no hearing protectors are taken into account.

Calculating the expanded uncertainty with an Excel program, associated with [41] and provided by the "Deutsches Institut für Normung e.V." (DIN), yields an expanded uncertainty of $3.0 \mathrm{~dB}(\mathrm{~A})$ for the MSA $220 \mathrm{C}$ and of $3.1 \mathrm{~dB}(\mathrm{~A})$ for the MS $201 \mathrm{C}[41,53]$. 


\section{Discussion}

Within this study, we compared the hand-arm vibration and noise exposure caused by a battery-powered and a combustion engine chainsaw, during a professional precommercial thinning operation. When interpreting the results of the trial, it is important to keep the performance range of both the chainsaws in mind. Although the machine data specify a similar classification for both units, allowing an appropriate comparison of the chainsaws, the actual performance range of the MS 201 C exceeds the one of the MSA 220 C. The manufacturer does not provide a rated power value for the MSA $220 \mathrm{C}$, but it is stated to be situated between the MS $201 \mathrm{C}$ (rated power of $1.8 \mathrm{~kW}$ ) and the MS $211 \mathrm{C}$ (rated power of $1.7 \mathrm{~kW}$ ) [54]. Regarding the chain speed, the MS $201 \mathrm{C}$ has an advantage of about $11.6 \%$ over the MSA $220 \mathrm{C}$. This benefit is, according to subjective assessments of the operator and the participants of the unpublished preceding study [20], clearly noticeable during work. Quantifying the influence of the performance difference on the vibration and noise exposure caused by both the chainsaws is hardly possible, but one should expect the higher performance to lead to slightly higher vibration and noise exposure. Similarly, the influence of the weight difference is difficult to judge. Generally, one should always favor lighter machines, as they lead to reduced strain for the operator. However, a reduced weight also leads to higher measured vibration levels [55]. Since the MSA $220 \mathrm{C}$ is, depending on the fuel and the tank level, about 13-19\% heavier than the MS 201 C, this puts the MS 201 C at a further disadvantage, regarding its vibration total values, although its lesser weight should be rated positively.

\subsection{Vibration Exposure}

The predominant activity during the productive work time was "Walking and orientation". Therefore, the vibration total values during this time influence the daily vibration exposure remarkably. There, the MSA $220 \mathrm{C}$ shows its strength, since the chainsaw is completely turned off at this time, and, in return, virtually no vibration exposure is experienced when walking or orientating oneself. The RMS VTV of about $0.9 \mathrm{~m} / \mathrm{s}^{2}$ results only from tilting and moving the chainsaw. In contrast, the MS $201 \mathrm{C}$ has nearly its highest vibration total values during these activities. This is caused by the chainsaw running in idle mode, which, for combustion-driven chainsaws, is generally the mode with the highest vibration values [11]. These high RMS VTVs, combined with the relatively long exposure time, are the main reason for the daily vibration exposure values of the MS $201 \mathrm{C}$ being far above the ones that were determined for the MSA $220 \mathrm{C}$.

The RMS VTVs for the front handle, while sawing, are very similar for both the machines. The MS $201 \mathrm{C}$ has a few outliers that are noticeably higher than the ones of the MSA $220 \mathrm{C}$, which could be related to the higher performance and chain speed. Nevertheless, the root mean square of the VTVs of the MSA $220 \mathrm{C}$ is slightly higher than the one of the MS $201 \mathrm{C}$, despite the performance and weight difference. The reason for this might be the anti-vibration system of the MS $201 \mathrm{C}$.

At the rear handle, the vibrations that were measured on the MS 201 C are significantly higher than the ones of the MSA $220 \mathrm{C}$. The difference cannot be explained by the differences in performance. Instead, it seems to be caused by the ergonomics of the rear handles. On the MS $201 \mathrm{C}$, the operator very frequently loosened his grip on the rear handle, while sawing (Figure 5). In comparison, the grip on the MSA $220 \mathrm{C}$ was way tighter (Figure 5) and never loosened in the same way. This is due to the positioning of the trigger lock (equivalent to the throttle lock of the combustion-driven chainsaw). The throttle lock of the MS $201 \mathrm{C}$ is on top of the rear handle (Figure 6) and is automatically unlocked when putting the hand on the handle. The throttle can then be pressed by using the thumb, while the other four fingers can loosen their grip. On the MSA $220 \mathrm{C}$, however, the trigger lock must be pressed with the thumb, since it is positioned on the left side at the front of the handle (Figure 6). Hence, the throttle is activated with the index finger, preventing the operator from loosening his grip, which, in turn, leads to a slight bending of the wrist (Figure 5). Holding this kind of position permanently during sawing, means an intensive 
ergonomic stress in a pre-commercial thinning, which requires frequent tilting movements of the chainsaw.
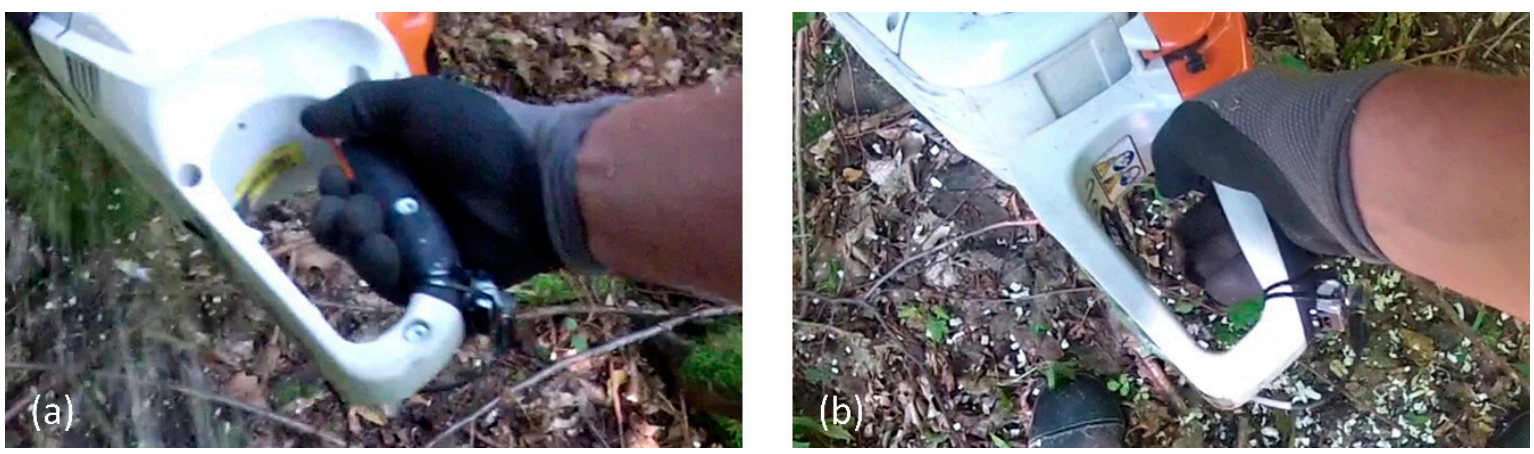

Figure 5. Hand position on the rear handle (a) of the MSA $220 \mathrm{C}$ and (b) the MS $201 \mathrm{C}$ while sawing.
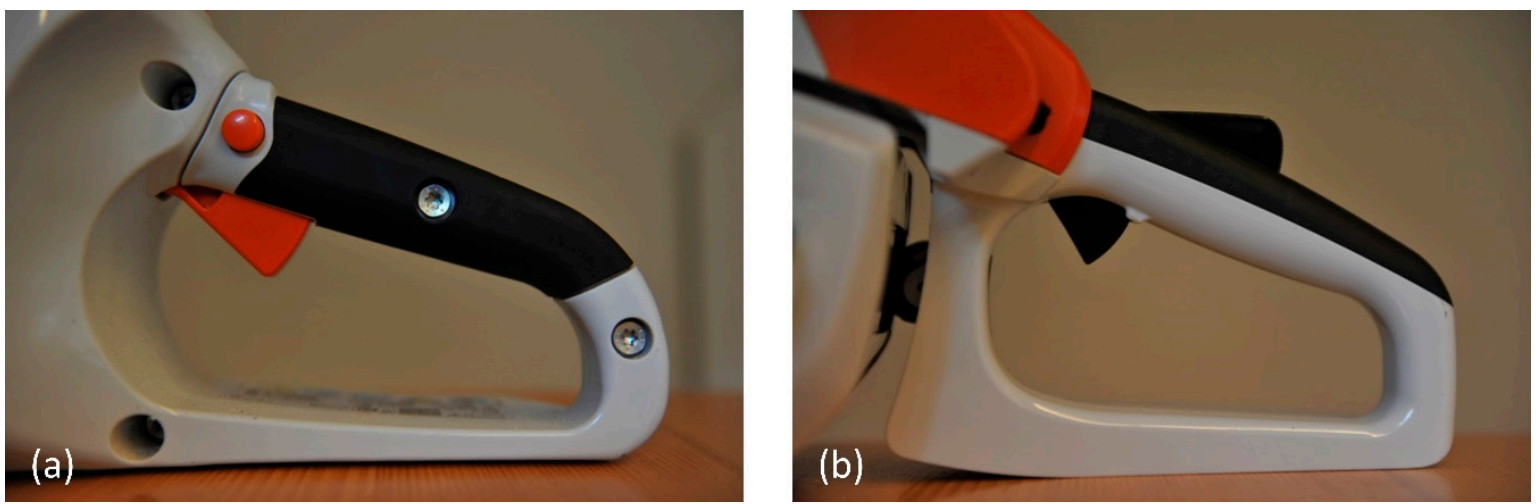

Figure 6. Position of (a) the trigger lock of the MSA $220 \mathrm{C}$ and (b) the throttle lock of the MS $201 \mathrm{C}$.

This makes the comparison of the vibration exposure on the rear handle quite impossible. Although the RMS VTVs of the MS $201 \mathrm{C}$ are much higher, the proportion of vibration intensity, which is transmitted to the hand-arm system of the operator, are heavily reduced because of the lower coupling force [56]. In general, higher coupling forces lead to a higher transmission of the vibrations to the hand-arm system, and therefore techniques and work tools that require lower coupling forces are preferred [57]. Especially amateurs, however, tend to exert higher coupling forces compared to professionals [14], and thereby are more prone to the risks caused by the chainsaw's vibrations. An attempt to consider the coupling forces, when regarding the vibration exposure, is to adjust the vibration exposure by a given factor, which depends on the exerted coupling force [58]. Accordingly, to correctly judge the vibration exposure in the given trial, it would have been essential to measure the coupling forces. A notable influence of differing coupling forces for both the chainsaws seems to be limited to the rear handle during the work element "Sawing" and some actions of work element two "Actions related to sawing". Nevertheless, measuring these forces, e.g., through a hydro-electronic force meter [59], provides perhaps the largest potential to enhance future studies.

The work element "Actions related to sawing" takes up only a small part of the productive work time. Therefore, its influence on the daily vibration exposure is limited. The main reason for introducing this work element is to avoid a distortion of the RMS VTVs for the first and third work elements. As many different actions fall into this work element, there are several effects influencing the values. During longer periods, the battery-powered chainsaw is turned off, whereas the combustion-driven chainsaw runs in idle mode. In these cases, the high RMS VTVs of the idle mode are the predominant reason for the worse results of the MS $201 \mathrm{C}$. Especially on the front handle, there are situations in which the idle mode generates very high vibration levels. These are caused by the operator loosening, 
or even releasing, his grip on the handle for a short time, when tilting the chainsaw from a vertical to horizontal position and vice versa, for example, before and after performing a cut. Hence, the handle can vibrate freely for a very short period. For the MSA $220 \mathrm{C}$, the effect only appeared when the chainsaw was running while being tilted, which happened seldom. Again, the measurement of the coupling forces would have been beneficial to correctly interpret the exposure.

The mentioned tilting and jerky movements, for example, when pulling out a trapped chainsaw, caused additional accelerations that were measured by the sensor. However, compared to the vibrations during idle mode, they are negligible. For the MSA $220 \mathrm{C}$, they are the main reason for a large part of the measured RMS VTVs in this work element.

Regarding work element four "Saw held on one handle", the procedure of considering the measured exposure time and assuming a vibration level of zero is not entirely correct, since the action of putting down the chainsaw and picking it up again is not considered. This would have a slight impact on the vibration values and on the time share of the different work elements. However, it would not change the general findings of this study. For the comparison of both the chainsaws, and for the comparability of the results with other studies, the procedure seems more adequate than considering the values measured during these times. If, however, the values would be considered as they were measured, considering the ones when no hand was touching the handle with an acceleration of $0 \mathrm{~m} / \mathrm{s}^{2}$, the daily vibration exposures would slightly increase, but maximally by about $2.1 \%$. Excluding the times entirely would increase the partial and daily vibration exposures by about 6.8 to $9.6 \%$, depending on the time share of the work element "Saw held on one handle".

Looking at the absolute values for the partial and daily vibration exposures, it becomes obvious that the daily vibration exposure caused by the MS $201 \mathrm{C}$ is not only high in comparison to the MSA $220 \mathrm{C}$, but that it is problematic in general, as it exceeds the daily exposure limit value at the rear handle. It does so partly because of the mentioned loosening of the grip, which distorts the results, but above all because of the very high partial vibration exposure of work element three "Walking and orientation". Even if a lower value would be considered for the first work element "Sawing", the value would be close to the limit. To illustrate this, assuming no other vibrations on a working day, about $4.4 \mathrm{~h}$ of "Walking and orientation" would already exceed the limit value, and the daily exposure action value would already be reached after $1.1 \mathrm{~h}$. The results on the front handle are not considerably better.

As a daily vibration exposure that is in the proximity of the limit value poses considerable health risks, the employer must take actions to reduce the exposure. One could be to reduce the exposure time, but as "Walking and orientation" makes up nearly half of the time of the workflow of pre-commercial thinning, the operator quickly reaches the exposure action value. The value is exceeded after about $1.85 \mathrm{~h}$ and $2.42 \mathrm{~h}$ of workplace time, at the rear and front handle, respectively. This corresponds to a productive work time of about $1.32 \mathrm{~h}$, i.e., a good two tank fillings, and $1.73 \mathrm{~h}$, i.e., nearly three tank fillings, respectively.

Another possible action is the use of anti-vibration gloves, though their influence on the vibration level is hardly possible to quantify, since it depends on many factors, such as, for example, the operator, the specific gloves, the grip force, the age of the gloves, the vibration frequencies and directions, and the specific tool [60,61]. Theoretical calculations, based on the vibration spectrum of a $4.9 \mathrm{~kg}$ heavy chainsaw in idle mode and the transmissibility spectrum of an air bladder anti-vibration glove, estimate the reduction in the weighted vibration transmission to be at about $14.2 \%$ for the vibrations transmitted to the palm and at about $4.3 \%$ for the transmission to the fingers [62]. However, in practice, the reduction might differ significantly and highly depends on the specific situation. Since there can also be drawbacks with wearing anti-vibration gloves, such as, for example, an amplified transmission, especially at low frequencies [63,64], higher coupling forces, or, because of the thickness and soft material, a more insecure handling of the chainsaw $[62,65]$, this makes contemplating the use of anti-vibration gloves extremely difficult. This is further 
complicated by the fact that the recent standard glove test might overestimate the total vibration reduction in anti-vibration gloves, while, at the same time, there are indications that the low weighting of high frequencies in the weighted vibration level might lead to an underestimation, especially when considering health risks for the fingers [62,64], concluding that further studies on that issue are needed.

Therefore, it is currently recommended to use anti-vibration gloves only in certain situations, in which a reduction in the vibration level has been proven or is actually to be expected. However, as with all personal protective equipment, anti-vibration gloves should only be considered as an additional measure, to contribute to a vibration reduction $[66,67]$.

For chainsaws, perhaps the biggest positive impact of the anti-vibration gloves is that they protect the hands from mechanical risks, and keep them warm and dry. This leads to better blood circulation in the hands and fingers, which is supposed to be a factor in reducing the risks caused by hand-arm vibrations. Obviously, this effect can also be achieved by wearing conventional gloves [66,67].

There is no danger of reaching the daily exposure limit value when working with the MSA $220 \mathrm{C}$, but the measured daily vibration exposure on the front handle of the MSA $220 \mathrm{C}$ is only barely below the daily exposure action value. Therefore, one should still have a close look at the vibration exposure and at options to further reduce the exposure, especially when considering the measurement uncertainty and the fact that other circumstances, such as the condition of the saw chain or the species of the felled tree, can increase the vibration levels [26].

In general, some drawbacks regarding the vibration measurements occurred, which were mainly caused by the available equipment. If the vibrations were measured on both handles at the same time, a much better comparison between the handles would have been possible. Furthermore, a third accelerometer would have been needed, to always measure the vibrations as close to the hand as possible. On the front handle, the frequent tilting of the chainsaws, to a horizontal position, led to a relatively large distance between the accelerometer and the hand (Figure 7). Because of the position of the sensor on the rear handle, jerky movements, especially when a tree suddenly gave way under load, could cause the operator to hit the sensor with his arm. This caused high peaks in the RMS VTVs, which had to be excluded from the evaluation, yet, this happened very seldom.

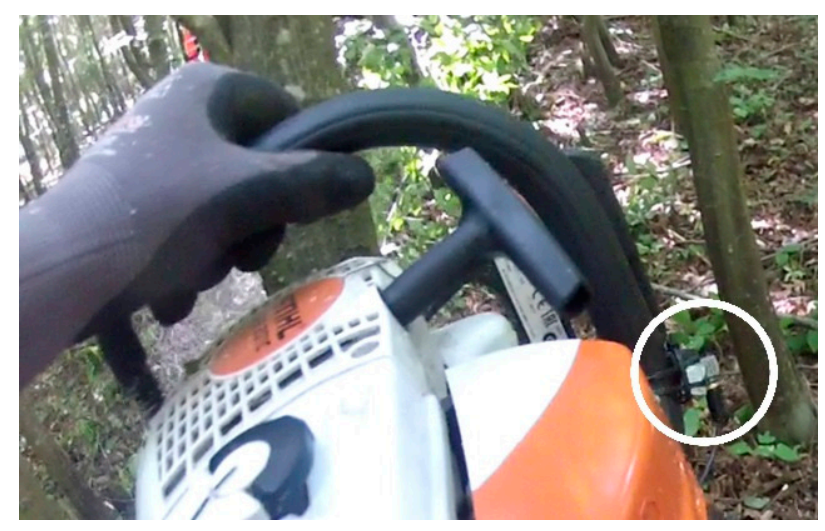

Figure 7. Distance of the accelerometer to the operator's hand on the front handle when the chainsaw is tilted.

Another issue was the length of the recorded measuring intervals. Since the RMS VTVs were only measured for one-second intervals, a precise assignment of the measured RMS VTVs to one of the work elements was not always possible.

The issue of assigning the values to the correct work element was further complicated by the fact that the time of the accelerometer and the camera were not running synchronously. The time of the accelerometer sometimes fell behind, by about half a second per minute. In most cases, the issue could be solved, but for the measurements on the rear 
handle of the MS 201 C, there were a few values for which the time difference prevented an unambiguous classification.

Nonetheless, the influence of these inaccuracies on the results is relatively small and does not change the general findings of this study, allocating the battery-powered MSA $220 \mathrm{C}$ a much better protection towards vibration-induced strain, compared to the combustion counterpart MS $201 \mathrm{C}$. However, the constructional characteristics of the MSA $220 \mathrm{C}$ bear potential to further reduce vibration exposure, as it does not have a built-in antivibration system as the MS $201 \mathrm{C}$ does. Yet, such an anti-vibration system should mainly focus on coupling forces that are transmitted from the saw chain and guide bar during sawing, and not from the piston movements, as it is required with the combustion engine only. Hence, new ergonomic design principles are needed for electric tools in professional use. The same applies to the handles and the trigger lock, having its origin in a consumergrade and arborist-focused product line, with special attention to high-safety functions. A better solution for the trigger lock, allowing multiple position changes without causing fatigue due to discomfortable wrist positions, is compulsory for professional utilization.

\subsection{Noise Exposure}

The $L_{\text {CPeak }}$ measurements of both the chainsaws demonstrate an obvious advantage of the battery-powered chainsaw, when considering the average peak sound pressure level of the measuring intervals. However, the data show that the MSA $220 \mathrm{C}$ can occasionally reach quite high sound pressure levels, above $115 \mathrm{~dB}(\mathrm{C})$, and can even get as loud as the MS 201 C. Yet, since the equivalent continuous sound pressure level was only recorded for one-minute intervals, it is not possible to completely rule out that the outliers, and especially the highest one, were not caused by chainsaw noise, but instead, for example, by a branch hitting the microphone. Overall, the $L_{C \text { Peak }}$ values are far below the legal requirements [42], and therefore are not of much concern by themselves. This is not true for the equivalent continuous sound pressure levels.

For the combustion chainsaw, the $L_{\text {Aeq }}$ of each measuring interval is higher than $90 \mathrm{~dB}(\mathrm{~A})$, and thereby above the $87 \mathrm{~dB}(\mathrm{~A})$ of the exposure limit value. Accordingly, the $L_{\mathrm{Ex}, 8 \mathrm{~h}}$ of $95.81 \mathrm{~dB}(\mathrm{~A})$ by far exceeds the upper exposure action value and, as long as no hearing protectors are taken into account, the exposure limit value, too, even if the lower bound of the interval that is defined by the expanded uncertainty of $3.1 \mathrm{~dB}(\mathrm{~A})$ is considered. In fact, the upper exposure action value is exceeded after not even half an hour of productive work time of an eight-hour working day, if an equivalent continuous sound pressure level of $65.43 \mathrm{~dB}(\mathrm{~A})$ is assumed for the rest of the time. Using the MSA $220 \mathrm{C}$, this time increases to a little more than two hours. This shows that although the $L_{\text {Aeq }}$ of the battery-powered chainsaw is far below the one of the MS 201 C, it is still not unproblematic. Even if the measurement uncertainty is taken into consideration, the lower threshold of the $L_{\text {Aeq }}$ for the battery chainsaw, during the productive work time, is still right above the exposure limit value. The lower border of the $L_{\mathrm{Ex}, 8 \mathrm{~h}}$ is just slightly under the limit, as long as no hearing protectors are taken into account. However, the $86.18 \mathrm{~dB}(\mathrm{~A})$ still surpass the upper exposure action value. Accordingly, preventive measures have to be applied for both the chainsaws, in order to protect the user [42]. However, it is important to mention that the linear operating range of the measuring equipment is between $65.0 \mathrm{~dB}(\mathrm{~A})$ and $140 \mathrm{~dB}(\mathrm{~A})$. None of the single measurements were above this range, but many values were below, causing a certain inaccuracy. This inaccuracy affected the values that were used for the calculation of the equivalent continuous sound pressure level during the delay and service times, as well as some measurements during the productive work time with the battery-powered chainsaw. In particular, when the MSA $220 \mathrm{C}$ was turned off, i.e., mainly when the operator was walking or orientating himself, the sound pressure level was often below $65.0 \mathrm{~dB}(\mathrm{~A})$.

There is likely one main reason explaining the differences in noise exposure, which is the combustion engine. The basic noise of combustion-driven chainsaws generally tops that of electric ones, since, usually, the exhaust noise is the loudest part of a combustion 
chainsaw. The intake noise and the chain noise are the next loudest noises [38]. Only the latter one is present in battery-powered chainsaws and is usually the prominent noise of such saws. As this chain noise is immanent to chainsaws, no matter what type of motor is used, it also represents a bound for the possible reduction in the noise level.

Another factor that stands out immediately, but is far less relevant, is that the MSA $220 \mathrm{C}$ is completely turned off when the operator is not sawing, while the MS $201 \mathrm{C}$ is still running in idle mode. A simplified calculation to estimate the effect of these periods on the equivalent continuous sound pressure level, looks as follows: Regarding the time shares, assume, generously calculated, that the battery-powered chainsaw was turned off and the combustion-driven chainsaw was in idle mode for about two thirds of the time, and that, therefore, the chainsaws were running about one third of the time. Further presume that the noise exposure that was caused by the MS $201 \mathrm{C}$ was $79 \mathrm{~dB}(\mathrm{~A})$ in idle mode and about $98 \mathrm{~dB}(\mathrm{~A})$ at full throttle [68]. Then, calculating an equivalent continuous sound pressure level yields a value of $93.34 \mathrm{~dB}(\mathrm{~A})$. If the equivalent continuous sound pressure level of the idle noise is replaced by an assumed background noise of $65 \mathrm{~dB}(\mathrm{~A})$, the equivalent continuous sound pressure level just reduces to $93.23 \mathrm{~dB}(\mathrm{~A})$. This illustrates that the periods during which the MSA $220 \mathrm{C}$ emits no noise, have a rather small influence on the total noise exposure. As the recorded noise levels in this trial were considerably higher than the ones used in the calculation, and the utilized measuring equipment does not provide the necessary information, a precise calculation of the influence on the recorded values is not possible. However, even if a relatively loud idle noise is presumed, it accounts for only a small part of the difference in the equivalent continuous sound pressure level of both the chainsaws. Yet, the periods with no noise emission by the MSA $220 \mathrm{C}$ were subjectively judged as great relief by the people involved in this study and by probands of the preceding one [20].

Certainly, the performance difference of both the chainsaws has an impact on the noise difference, too, but, as already mentioned, it is hardly possible to estimate the quantity. Though, its magnitude cannot explain the significant difference in noise exposure.

The biggest drawback of the noise measurements was the restriction in the $L_{\text {Aeq }}$ measurements of the one-minute intervals related to the available equipment. Because of this, nearly $15 \%$ of the productive work time could not be used for the evaluation, since the corresponding measuring intervals included productive work time, and delay and service times, which could not be separated from each other. Additionally, it prevented the filtering of possible outliers and an analysis of the noise levels during different activities, as well as their influence on the daily noise exposure. Nevertheless, the results provide important general insights into noise exposure during practical use. They show a significant advantage of the battery-powered chainsaw compared to the combustion-driven chainsaw. As expected, the advantage is far greater than the difference in the performance of both the chainsaws. Therefore, the study provides further hints that replacing combustion chainsaws with battery-powered ones reduces the health risks for workers. However, for a full working day of pre-commercial thinning, the use of both chainsaws requires the user to wear hearing protections. By utilizing appropriate hearing protectors, the daily exposure value can be reduced to the desired level of 70 to $80 \mathrm{~dB}(\mathrm{~A})$ for both the chainsaws [69].

\subsection{Operational Remarks}

Battery-powered chainsaws, already attracting urban arborists for some years, have just entered the professional forestry sector, with the investigated STIHL MSA $220 \mathrm{C}$ being in the position to compete with well-established combustion models, at least in the lower-capacity classes focusing on early thinning operations. Also, other well-known manufacturers, such as the recently released Husqvarna 540i XP, with a capacity range approaching the MSA $220 \mathrm{C}$, are targeting professional users in the forestry sector [70]. The confirmed ergonomic benefits, in terms of vibration and noise exposure, as well as the obvious lack of exhaust fumes, are a release towards the occupational hazards of the operator, although further constructional improvements are still possible. 
Yet, despite the introduction of more powerful electric drives and Li-ion batteries of high voltage, with management systems to adapt the current for constant power supply [71], the battery technology itself will remain a considerable shortfall for the work in the forest. Being off the grid, recharging is a challenge, and the only feasible solution is, indeed, to have multiple batteries available, to ensure constant work over the full day. That does not necessarily mean much of a price premium, since electricity is cheap compared to alkylate fuels, and the costs for additional batteries will be generated within professional use in a reasonable time period. However, the pure handling in the terrain and under outdoor conditions with exposure to moist or dust, but also hot or cold environments, will affect the performance of the tools, and further, the workflow of the operator. Backpack batteries, such as the STIHL AR 3000 L [72], or the Makita Portable Power Pack PDC01 [73], are intermediate solutions to increase the range of the operation period. However, the extra weight of around $10 \mathrm{~kg}$ and the required cord adapter, will not only add a disturbing feature, but it can also further cause additional strain on the muscular-skeletal system and even safety risks. Therefore, certainly even more powerful battery saws, with numerous benefits, will be available within the coming years, and further improve upon the human factors of motor-manual forest operations. However, if no profound technical or logistical solutions are developed, to solve the electric energy supply constraints in the forest, battery saws will remain in the shade of combustion units.

\section{Conclusions}

The presented study allows the following key findings to be generally concluded:

- Battery-powered chainsaws can lead to a considerable reduction in vibration and noise exposure;

- The vibration and noise exposure of battery-powered chainsaws might often be underestimated;

- Hearing protection and glove use is recommended during all operating times.

Therefore, from an occupational health and safety point of view, battery-powered chainsaws should be given preference over combustion-driven ones whenever possible. This applies, in particular, to tasks such as pre-commercial thinning or other tasks during which the battery-powered chainsaw can be turned off frequently, whereas the combustiondriven chainsaw would run in idle mode. During tasks where the majority of the time is composed by sawing, the reduction in vibration exposure is expected to be far less, if it exists at all, yet there will still be a considerable reduction in noise exposure.

Battery-powered chainsaws should, however, not be underestimated with respect to the exposition of users to vibration and noise, as the saw chain inherently is a considerable source of noise and vibration. The daily vibration exposure of the MSA $220 \mathrm{C}$, for a full working day of pre-commercial thinning, still ends up in the neighborhood of the daily exposure action value, and the daily noise exposure even exceeds the upper exposure action value, making the use of hearing protectors necessary.

Author Contributions: Conceptualization, F.B., S.H. and M.H.; methodology, M.H., F.B. and S.H.; measuring equipment, F.H. and D.J.; formal analysis, M.H.; investigation, F.B., F.H., S.H. and M.H.; writing-original draft preparation, M.H., S.H. and F.B.; writing-review and editing, M.H., S.H., F.B., F.H., D.J. and U.H.S.; visualization, M.H.; supervision, D.J. and U.H.S. All authors have read and agreed to the published version of the manuscript.

Funding: Part of the publication costs were funded by the Eva Mayr-Stihl Stiftung, Waiblingen, Germany.

Data Availability Statement: The data presented in this study are available on request from the corresponding author. The data are not publicly available due to privacy restrictions.

Acknowledgments: We kindly acknowledge the ForstBW forestry training center Koenigsbronn/Germany (FBZ Königsbronn) and STIHL (Stihl Holding AG \& Co. KG Waiblingen/Germany), for providing the test saws to be used within the trial. Additionally, we thank the Institute for Occupational Safety and Health of the German Social Accident Insurance-IFA (Institut für Arbeitsschutz der 
Deutschen Gesetzlichen Unfallversicherung) for providing technical support and the noise dosemeter. In particular, our thanks go to Uwe Kaulbars, Andrea Wolff and Christoph Knipfer from IFA for their advice and suggestions. We are particularly grateful for the support of the forestry district Emmendingen and its staff, especially the support of the proband, without whose commitment the trial would not have been possible. Further thanks go to Uwe Uhlich and the Chair of Forest Operations of the Albert-Ludwigs University Freiburg as well as to the research assistants of the Forest Research Institute of Baden-Württemberg-FVA (Forstliche Versuchs- und Forschungsanstalt Baden-Württemberg) for their participation in the field trial and their support with analyzing the video footage. We acknowledge Robin Feldmann for his contribution by realizing his master thesis within the framework of this project.

Conflicts of Interest: The authors declare no conflict of interest. The funders had no role in the design of the study; in the collection, analyses, or interpretation of data; in the writing of the manuscript, or in the decision to publish the results.

\section{References}

1. Slappendel, C.; Laird, I.; Kawachi, I.; Marshall, S.; Cryer, C. Factors affecting work-related injury among forestry workers: A review. J. Saf. Res. 1993, 24, 19-32. [CrossRef]

2. Tsioras, P.A.; Rottensteiner, C.; Stampfer, K. Wood harvesting accidents in the Austrian State Forest Enterprise 2000-2009. Saf. Sci. 2014, 62, 400-408. [CrossRef]

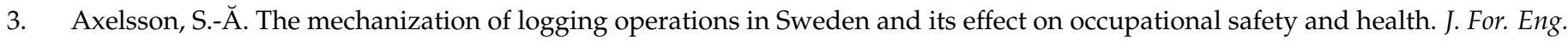
1998, 9, 25-31.

4. Labelle, E.R.; Lemmer, K.J. Selected Environmental Impacts of Forest Harvesting Operations with Varying Degree of Mechanization. Croat. J. For. Eng. J. Theory Appl. For. Eng. 2019, 40, 239-257. [CrossRef]

5. Müller, F.; Jaeger, D.; Hanewinkel, M. Digitization in wood supply-A review on how Industry 4.0 will change the forest value chain. Comput. Electron. Agric. 2019, 162, 206-218. [CrossRef]

6. Berendt, F.; Hoffmann, S.; Jaeger, D.; Prettin, S.; Schweier, J. Application of spiroergometry to determine work metabolism related strain in the course of cable work with a mini forestry crawler. Int. J. For. Eng. 2020, 31, 114-125. [CrossRef]

7. Potočnik, I.; Poje, A. Forestry ergonomics and occupational safety in high ranking scientific journals from 2005-2016. Croat. J. For. Eng. J. Theory Appl. For. Eng. 2017, 38, 291-310.

8. Dimou, V.; Kantartzis, A.; Malesios, C.; Kasampalis, E. Research of exhaust emissions by chainsaws with the use of a portable emission measurement system. Int. J. For. Eng. 2019, 30, 228-239. [CrossRef]

9. Magnusson, R.; Nilsson, C. The influence of oxygenated fuels on emissions of aldehydes and ketones from a two-stroke spark ignition engine. Fuel 2011, 90, 1145-1154. [CrossRef]

10. Poje, A.; Potočnik, I.; Mihelič, M. Comparison of Electric and Petrol Chainsaws in Terms of Efficiency and Safety When Used in Young Spruce Stands in Small-Scale Private Forests. Small Scale For. 2018, 17, 411-422. [CrossRef]

11. Rottensteiner, C.; Stampfer, K. Evaluation of operator vibration exposure to chainsaws equipped with a Kesper safety bar. Scand. J. For. Res. 2013, 28, 193-200. [CrossRef]

12. Griffin, M.J. Minimum health and safety requirements for workers exposed to hand-transmitted vibration and whole-body vibration in the European Union; a review. Occup. Environ. Med. 2004, 61, 387-397. [CrossRef] [PubMed]

13. Malinowska-Borowska, J.; Harazin, B.; Zieliński, G. The influence of wood hardness and logging operation on coupling forces exerted by lumberjacks during wood harvesting. Int. J. Ind. Ergon. 2011, 41, 546-550. [CrossRef]

14. Malinowska-Borowska, J.; Zieliński, G. Coupling forces exerted on chain saws by inexperienced tree fellers. Int. J. Ind. Ergon. 2013, 43, 283-287. [CrossRef]

15. Kováč, J.; Krilek, J.; Dado, M.; Beňo, P. Investigating the influence of design factors on noise and vibrations in the case of chainsaws for forestry work. FME Trans. 2018, 46, 513-519. [CrossRef]

16. Fonseca, A.; Aghazadeh, F.; de Hoop, C.; Ikuma, L.; Al-Qaisi, S. Effect of noise emitted by forestry equipment on workers' hearing capacity. Int. J. Ind. Ergon. 2015, 46, 105-112. [CrossRef]

17. Neri, F.; Foderi, C.; Laschi, A.; Fabiano, F.; Cambi, M.; Sciarra, G.; Aprea, M.C.; Cenni, A.; Marchi, E. Determining exhaust fumes exposure in chainsaw operations. Environ. Pollut. 2016, 218, 1162-1169. [CrossRef] [PubMed]

18. Neri, F.; Laschi, A.; Foderi, C.; Fabiano, F.; Bertuzzi, L.; Marchi, E. Determining noise and vibration exposure in conifer cross-cutting operations by using li-ion batteries and electric chainsaws. Forests 2018, 9, 501. [CrossRef]

19. Andreas Stihl AG \& Co KG. STIHL MSA 220 C Gebrauchsanleitung; Andreas Stihl AG \& Co KG: Waiblingen, Germany, 2018.

20. Brieger, F.; Fei, J.; Sauter, F.; Sauter, U.H. Vorstudie zum Einsatz von Akku-Motorsägen in der Jungbestandspflege; Projektbericht, FVA-Waldnutzung; Unpublished; 2021.

21. Marchi, E.; Chung, W.; Visser, R.; Abbas, D.; Nordfjell, T.; Mederski, P.S.; McEwan, A.; Brink, M.; Laschi, A. Sustainable Forest Operations (SFO): A new paradigm in a changing world and climate. Sci. Total Environ. 2018, 634, 1385-1397. [CrossRef]

22. Andreas Stihl AG \& Co KG. STIHL MS 201 C-M Gebrauchsanleitung; Andreas Stihl AG \& Co KG: Waiblingen, Germany, 2019. 
23. Stihl Vertriebszentrale AG \& Co. KG. Akku AP 300 S. Available online: https://www.stihl.de/de/ap/akku-ap-300-s-88828 (accessed on 12 March 2021).

24. Stihl Vertriebszentrale AG \& Co. KG. Kettensägen/Motorsägen: MS 201. Available online: https://www.stihl.de/de/p/ kettensaegen-motorsaegen-ms-201-43584 (accessed on 12 March 2021).

25. Stihl Vertriebszentrale AG \& Co. KG. Kettensägen/Motorsägen: MSA 220_AP-System. Available online: https://www. stihl.de/de/p/kettensaegen-motorsaegen-msa-220-ap-system-102688\#c-b-ohne-akku-ohne-ladegeraet-102688 (accessed on 15 December 2020).

26. Marenče, J.; Mihelic, M.; Poje, A. Influence of Chain Filing, Tree Species and Chain Type on Cross Cutting Efficiency and Health Risk. Forests 2017, 8, 464. [CrossRef]

27. Stempski, W.; Jabłoński, K.; Wegner, J. Relations between top-plate filling angle values of cutting chains and chainsaw vibration levels. Acta Sci. Pol. 2010, 9, 31-39.

28. Deutsches Institut für Normung e.V. DIN EN ISO 5349-1:2001-12; Mechanische Schwingungen-Messung und Bewertung der Einwirkung von Schwingungen auf das Hand-Arm-System des Menschen-Teil 1: Allgemeine Anforderungen (ISO 5349-1:2001); Beuth: Berlin, Germany, 2001. [CrossRef]

29. Deutsches Institut für Normung e.V. DIN EN ISO 5349-2:2015-12; Mechanische Schwingungen-Messung und Bewertung der Einwirkung von Schwingungen auf das Hand-Arm-System des Menschen-Teil 2: Praxisgerechte Anleitung zur Messung am Arbeitsplatz (ISO 5349-2:2001 + Amd 1:2015); Beuth: Berlin, Germany, 2015. [CrossRef]

30. Brüel \& Kjær Sound \& Vibration Measurement A/S. Daten und Fakten: Humanschwingungsanalysator—Typ 4447; Brüel \& Kjær Sound \& Vibration Measurement A/S: Nærum, Denmark, 2009.

31. Brüel \& Kjær Sound \& Vibration Measurement A/S. Catalogue—Transducers and Conditioning; Brüel \& Kjær Sound \& Vibration Measurement A/S: Nærum, Denmark, 2016.

32. Brüel \& Kjær Sound \& Vibration Measurement A/S. Technische Dokumentation: Humanschwingungsanalysator Typ 4447; Brüel \& Kjær Sound \& Vibration Measurement A/S: Nærum, Denmark, 2009.

33. European Parliament; Council of the European Union. Directive 2002/44/EC of the European Parliament and of the Council of 25 June 2002 on the minimum health and safety re-quirements regarding the exposure of workers to the risks arising from physical agents (vibration) (sixteenth individual Di-rective within the meaning of Article 16(1) of Directive 89/391/EEC). Off. J. Eur. Commun. 2002, 45, 13-20.

34. Deutsches Institut für Normung e.V. DIN EN ISO 22867:2012-04; Forst- und Gartenmaschinen-Schwingungsmessnorm für Handgehaltene Maschinen mit Verbrennungsmotor—Schwingungen an den Handgriffen; Beuth: Berlin, Germany, 2012. [CrossRef]

35. Deutsches Institut für Normung e.V. DIN EN 60745-2-13:2011-07; Handgeführte Motorbetriebene Elektrowerkzeuge-Sicherheit-Teil 2-13: Besondere Anforderungen für Kettensägen (IEC 60745-2-13:2006, Modifiziert + A1:2009); Beuth: Berlin, Germany, 2011.

36. Goglia, V.; Suchomel, J.; Žgela, J.; Đukić, I. The effectiveness of forest pre-commercial thinning in the context of Directive 2002/44/EC. Sumar. List 2012, 136, 471-478.

37. Kaulbars, U. Gefährdungsbeurteilung der Hand-Arm-Vibration bei der Waldarbeit mit Motorkettensägen, 2nd ed.; IFA Report, 5/2015; Deutsche Gesetzliche Unfallversicherung e.V. (DGUV): Sankt Augustin, Germany, 2015.

38. Forstliche Bildungsstätten der Bundesrepublik Deutschland. Der Forstwirt, 6th ed; Eugen Ulmer KG: Stuttgart, Germany, 2015; ISBN 978-3-8001-8448-4.

39. Casella UK Office. CEL-35x dBadge Users Handbook; Casella UK Office: Bedford, UK, 2015.

40. Maue, J.H. Lärmmessung im Betrieb: Anleitung zur Normgerechten Ermittlung der Lärmexposition am Arbeitsplatz und der Geräuschemission von Maschinen; Erich Schmidt Verlag GmbH \& Co. KG: Berlin, Germany, 2011; ISBN 978-3-503-13007-8.

41. Deutsches Institut für Normung e.V. DIN EN ISO 9612:2009-09; Akustik-Bestimmung der Lärmexposition am Arbeitsplatz-Verfahren der Genauigkeitsklasse 2 (Ingenieurverfahren) (ISO 9612:2009); Beuth: Berlin, Germany, 2009. [CrossRef]

42. European Parliament, Council of the European Union. Directive 2003/10/EC of the European Parliament and of the Council of 6 February 2003 on the minimum health and safety requirements regarding the exposure of workers to the risks arising from physical agents (noise) (seventeenth individual Directive within the meaning of Article 16(1) of Directive 89/391/EEC). Off. J. Eur. Commun. 2003, 46, 38-44.

43. Bundesministerium der Justiz und für Verbraucherschutz. Lärm- und Vibrations-Arbeitsschutzverordnung—LärmVibrationsArbSchV; BGBl. I S. 261, last edited by Art. 5 Abs. 5 of the regulation on 18 October 2017, BGBl. I S. 3584; Bundesministerium der Justiz und für Verbraucherschutz: Berlin, Germany, 2007.

44. Casella. Casella dBadge Lärmdosimeter_Datenblatt; Casella: Bedford, UK, 2013.

45. Crocker, M.J.; Arenas, J.P. Engineering Acoustics: Noise and Vibration Control; Wiley: Hoboken, NJ, USA, 2021; ISBN 978-1-1184-9642-8.

46. TSI Incorporated. The Impact of Threshold, Criterion Level and Exchange Rate on Noise Exposure Data Results; Application Note Quest-001; TSI Incorporated: Shoreview, MN, USA, 2020.

47. Feldmann, R. Vibrations- und Schallemissionen von Akkumotorsägen in der Jungbestandspflege. Master's Thesis, AlbertLudwigs-Universität Freiburg, Freiburg, Germany, 2019.

48. R Core Team. R: A Language and Environment for Statistical Computing; R Foundation for Statistical Computing: Vienna, Austria, 2020. Available online: https:/ / www.R-project.org/ (accessed on 17 June 2021).

49. RStudio Team. RStudio: Integrated Development Environment for R; RStudio, PBC: Boston, MA, USA, 2020. Available online: http:/ / www.rstudio.com/ (accessed on 17 June 2021). 
50. Kassambara, A. ggpubr: 'ggplot2' Based Publication Ready Plots, R Package Version 0.4.0. 2020. Available online: https: / / cran.r-project.org/package=ggpubr (accessed on 17 June 2021).

51. Schauberger, P.; Walker, A. Openxlsx: Read, Write and Edit xlsx Files, R Package Version 4.1.5. 2020. Available online: https:/ / cran.r-project.org/package=openxlsx (accessed on 17 June 2021).

52. Wickham, H. ggplot2: Elegant Graphics for Data Analysis; Springer: New York, NY, USA, 2016; ISBN 978-3-319-24277-4. Available online: https: / ggplot2.tidyverse.org (accessed on 17 June 2021).

53. Deutsches Institut für Normung e.V. Kalkulationsprogramm zur DIN EN ISO 9612:2009-09 (Unsicherheiten). 2015. Available online: https:/ / www.din.de/de/mitwirken/normenausschuesse/nals/kalkulationsprogramm-zur-din-en-iso-9612-2009-09 -unsicherheiten--90316 (accessed on 25 November 2020).

54. Jäger, M. Stihl MSA 220 C-B im Test: Akku-Kettensäge für Professionelle Ansprüche. Available online: https://www.chip.de/ test/Stihl-MSA-220-C-B-im-Test_182903473.html (accessed on 15 December 2020).

55. Malchaire, J.; Piette, A.; Moens, G.; Boodts, S.; Cornillie, F.; Delaruelle, D.; de Cooman, G.; Timmerman, I.; Carlier, P.; Mathy, F.; et al. Vibrations Mains-Bras: Serie Strategie Sobane—Gestion des Risques Professionnels; SPF Emploi, Travail et Concertation sociale: Brussels, Belgium, 2020.

56. Kaulbars, U.; Scheffer, M. Forschungsbericht Hand-Arm-Schwingungen III Wirkung von Greif- und Andruckkraft unter Schwingungsbelastung; Hauptverband der Gewerblichen Berufsgenossenschaften: Sankt Augustin, Germany, 1992; ISBN 3-88383-309-6.

57. Bundesanstalt für Arbeitsschutz und Arbeitsmedizin. Technische Regeln zur Lärm- und Vibrations-Arbeitsschutzverordnung: TRLV Vibrationen-Teil 1: Beurteilung der Gefährdung durch Vibrationen; GMBl 2015 Nr. 25/26 2015, Ausgabe März; Bundesministerium des Innern, für Bau und Heimat: Berlin, Germany, 2015.

58. Deutsches Institut für Normung e.V. DIN 45679:2013-02; Mechanische Schwingungen-Messung und Bewertung der Ankopplungskräfte zur Beurteilung der Schwingungsbelastung des Hand-Arm-Systems; Beuth: Berlin, Germany, 2013.

59. Malinowska-Borowska, J.; Harazin, B.; Zieliński, G. Measuring Coupling Forces Woodcutters Exert on Saws in Real Working Conditions. Int. J. Occup. Saf. Ergon. 2012, 18, 77-83. [CrossRef]

60. Hewitt, S.; Dong, R.; McDowell, T.; Welcome, D. The efficacy of anti-vibration gloves. Acoust. Aust. 2016, 44, 121-127. [CrossRef] [PubMed]

61. Shibata, N. Effect of shelf aging on vibration transmissibility of anti-vibration gloves. Ind. Health 2017, 55, 575-579. [CrossRef] [PubMed]

62. Hewitt, S.; Dong, R.G.; Welcome, D.E.; McDowell, T.W. Anti-vibration gloves? Ann. Occup. Hyg. 2014, 59, 127-141.

63. McDowell, T.W.; Dong, R.G.; Welcome, D.E.; Xu, X.S.; Warren, C. Vibration-reducing gloves: Transmissibility at the palm of the hand in three orthogonal directions. Ergonomics 2013, 56, 1823-1840. [CrossRef] [PubMed]

64. Welcome, D.E.; Dong, R.G.; Xu, X.S.; Warren, C.; McDowell, T.W. Tool-specific performance of vibration-reducing gloves for attenuating fingers-transmitted vibration. Occup. Ergon. 2016, 13, 23-44. [CrossRef]

65. Kaulbars, U.; Walther, C. Certified anti-vibration gloves: Test methods and the limits to their effectiveness. In Proceedings of the 20th Japan Conference on Human Response to Vibration, Osaka, Japan, 4-6 September 2012.

66. Kaulbars, U. Vibrations-Schutzhandschuhe haben begrenzte Wirkung. MM Masch. 2010, 19, 30-32.

67. Health and Safety Executive. Hand Arm Vibration in Forestry and Arboriculture. Available online: https://www.hse.gov.uk/ treework/health/hand-arm-vibration.htm (accessed on 26 March 2021).

68. Kuratorium für Waldarbeit und Forsttechnik e.V. Prüfbericht: Stihl MS 201/MS 201 C E Stihl MS 201 C-M/MS 201 C-EM; Kuratorium für Waldarbeit und Forsttechnik e.V: Groß-Umstadt, Germany, 2019.

69. Deutsche Gesetzliche Unfallversicherung e.V. DGUV Regel 112-194: Benutzung von Gehörschutz; Deutsche Gesetzliche Unfallversicherung e.V: Berlin, Germany, 2015.

70. Höllerl, H. Akkupower. ForstTech 2020, 3.2020, 15-17.

71. Pandur, Z.; Šušnjar, M.; Bačić, M. Battery Technology. Croat. J. For. Eng. J. Theory Appl. For. Eng. 2021, 42, 135-148. [CrossRef]

72. STIHL Vertriebszentrale AG \& Co. KG. AR 3000 L Backpack Battery, Set with Connecting Cable and AP Adapter. Available online: https:/ / www.stihl.de/de/ap/rueckentragbarer-akku-ar-3000-1-95347 (accessed on 15 December 2020).

73. Makita Corporation. Portable Power Pack PDC01. Available online: https://www.makita.com.sg/product/pdc01-portablepower-pack/ (accessed on 15 December 2020). 